\title{
BMJ
}

\section{Effects of treatment in women with gestational diabetes mellitus: systematic review and meta-analysis}

\begin{abstract}
Karl Horvath, project manager EBM review center, ${ }^{1}$ head of outpatient facility diabetes and metabolism, ${ }^{2}$ Klaus Koch, project manager, ${ }^{3}$ Klaus Jeitler, scientific assistant, ${ }^{1}$ Eva Matyas, scientific assistant, ${ }^{1}$ Ralf Bender, head of department of medical biometry, ${ }^{3}$ Hilda Bastian, head of department of health information, ${ }^{3}$ Stefan Lange, deputy director, ${ }^{3}$ Andrea Siebenhofer, professor for chronic care and health services research, ${ }^{4}$ project manager $^{1}$
\end{abstract}

\section{ABSTRACT}

Objective To summarise the benefits and harms of treatments for women with gestational diabetes mellitus.

Design Systematic review and meta-analysis of randomised controlled trials.

Data sources Embase, Medline, AMED, BIOSIS, CCMed, CDMS, CDSR, CENTRAL, CINAHL, DARE, HTA, NHS EED, Heclinet, SciSearch, several publishers' databases, and reference lists of relevant secondary literature up to October 2009.

Review methods Included studies were randomised controlled trials of specific treatment for gestational diabetes compared with usual care or "intensified" compared with "less intensified" specific treatment. Results Five randomised controlled trials matched the inclusion criteria for specific versus usual treatment. All studies used a two step approach with a $50 \mathrm{~g}$ glucose challenge test or screening for risk factors, or both, and a subsequent $75 \mathrm{~g}$ or $100 \mathrm{~g}$ oral glucose tolerance test. Meta-analyses did not show significant differences for most single end points judged to be of direct clinical importance. In women specifically treated for gestational diabetes, shoulder dystocia was significantly less common (odds ratio $0.40,95 \%$ confidence interval 0.21 to 0.75 ), and one randomised controlled trial reported a significant reduction of pre-eclampsia $(2.5 \vee 5.5 \%$, $\mathrm{P}=0.02)$. For the surrogate end point of large for gestational age infants, the odds ratio was 0.48 (0.38 to 0.62 ). In the 13 randomised controlled trials of different intensities of specific treatments, meta-analysis showed a significant reduction of shoulder dystocia in women with more intensive treatment $(0.31,0.14$ to 0.70$)$. Conclusions Treatment for gestational diabetes, consisting of treatment to lower blood glucose concentration alone or with special obstetric care, seems to lower the risk for some perinatal complications. Decisions regarding treatment should take into account that the evidence of benefit is derived from trials for which women were selected with a two step strategy (glucose challenge test/screening for risk factors and oral glucose tolerance test).

\section{INTRODUCTION}

Gestational diabetes mellitus, defined as "carbohydrate intolerance of varying degrees of severity with onset or first recognition during pregnancy,"1 is associated with an increased risk of complications for mother and child during pregnancy and birth. ${ }^{2}$ Among those complications are shoulder dystocia and birth injuries, neonatal hyperbilirubinaemia, hypoglycaemia, respiratory distress syndrome, caesarean section, and pre-eclampsia. ${ }^{2}$ Fetal macrosomia is associated with gestational diabetes ${ }^{2}$ and is a surrogate for many of the complications. Epidemiological research suggests that women who have gestational diabetes have an increased risk of type 2 diabetes later in life. ${ }^{3}$

Diagnosis of gestational diabetes is commonly based on the results of oral glucose tolerance tests. Depending on cut-off values, ethnicity, and other factors, the prevalence in the US is estimated to be $7 \% 0^{4}$ and is thought to be increasing. ${ }^{5}$

Specific treatment, consisting of treatment to lower glucose concentrations and special obstetric management, is recommended to reduce the risk to mothers and infants during pregnancy and later in life. But it remains controversial which outcomes can be influenced. Also, it is still unclear which affected women, and their offspring, with what degree of maternal carbohydrate intolerance, will benefit from treatment. This uncertainty is reflected in the fact that various screening strategies and diagnostic criteria are used to identify women with gestational diabetes mellitus. ${ }^{6-10}$

The main options for diagnosis are a one step oral glucose tolerance test (either taking measurements at fasting, one and/or two hours after $75 \mathrm{~g}$ glucose, or at fasting, one, two, and three hours after $100 \mathrm{~g}$ ) or a two step strategy. This entails screening with either a list of risk factors or a one hour $50 \mathrm{~g}$ glucose challenge test and then an oral glucose tolerance test only in those women with positive results. Women's preferences have not been systematically studied.

We conducted a systematic review to determine what possible beneficial effects can be achieved by specific 


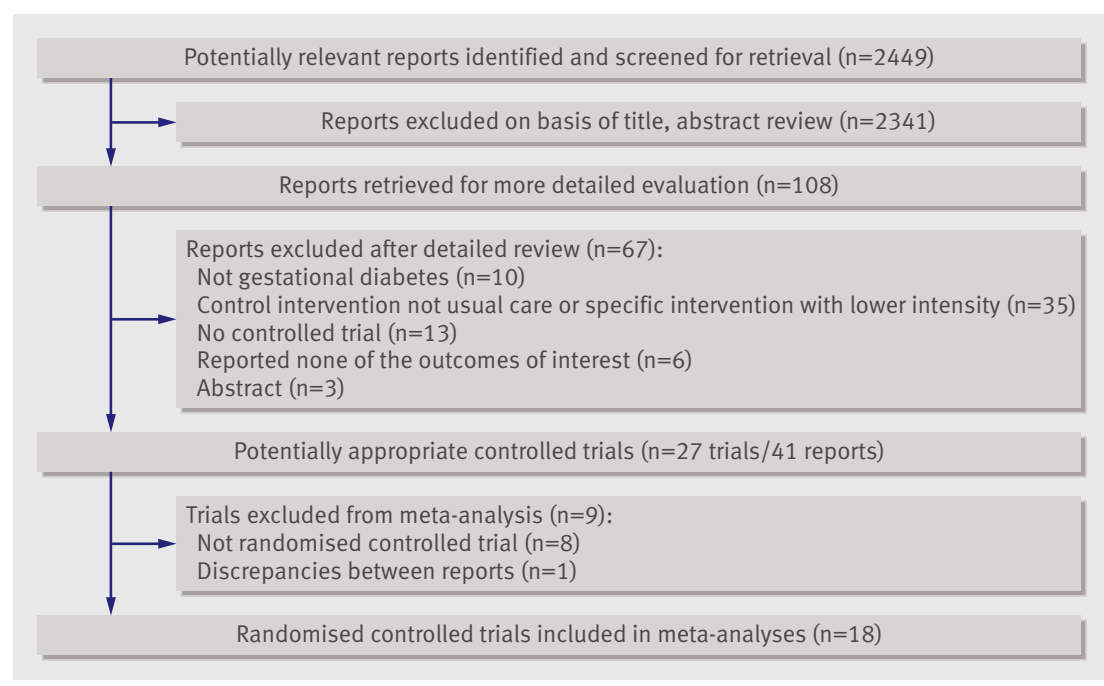

Fig 1 | Flowchart of article selection in trial

treatment of gestational diabetes and which women and their offspring will benefit from such treatment. We included treatments aimed at lowering blood glucose concentration with or without specific obstetric interventions, such as routine induction of labour. We gave special consideration to the selection strategies used to recruit women for the intervention trials.

\section{METHODS}

Our main aim was to assess the effects of specific interventions for gestational diabetes on the risk of pregnancy, perinatal, and long term complications in pregnant women with carbohydrate intolerance identified by a glucose tolerance test. Benefit from treatment in these women is a prerequisite for effectiveness of a screening programme for gestational diabetes.

\section{Inclusion and exclusion criteria}

To be eligible for inclusion in our systematic review, studies had to examine specific treatment for gestational diabetes compared with usual care or "intensified" specific treatment with "less intensified" specific care, had to include pregnant women with an impairment of their glucose tolerance (based on the results of an oral glucose tolerance test), and had to report on at least one outcome of interest (see below). We included only randomised trials.

As one would not expect to see an effect of an intervention in studies aimed at non-inferiority or equivalence for the head-to-head treatment comparisons, we excluded trials if there was no clear difference in intensity (for example, additional treatment, earlier treatment, earlier and more frequent treatment, lower target concentrations for blood glucose, special neonatal care, etc) of interventions planned.

\section{Search}

We carried out a literature search using Embase, Embase Alert, Medline, AMED, BIOSIS, BIOS
IS Preview, CCMed, CDMS, CDSR, CENTRAL, CINAHL, DARE, HTA, NHS EED, Heclinet, Journals@Ovid Full Text, SciSearch, publishers' databases (Hogrefe, Karger, Kluwer, Krause and Pachernegg, Springer, Thieme), and the reference lists of relevant secondary literature up to October 2009.

Multiple teams of two reviewers (AS, KH, KJ, EM, and/or additional researchers) independently screened the title, abstract, and key words of each reference identified by the search and applied the inclusion and exclusion criteria. For potentially eligible references the same procedure was applied to full text articles. Differences between reviewers were resolved by discussion or a third reviewer (AS, KH, KJ, EM, UP, KK). Data on quality, patients' characteristics, interventions, and relevant outcomes were independently abstracted by two reviewers (AS, KH, KJ, EM, UP, and/or KK).

Assessment of risk of bias was based on the adequacy of randomisation, allocation concealment, blinding of outcome assessors, comparability of women in the different intervention groups for prognostically relevant factors at baseline, and handling of missing values (such as withdrawals and drop outs). As gestational diabetes is treated by complex interventions that are not amenable to blinding, we did not consider lack of blinding of patients and study staff to be a major flaw. Differences between reviewers were resolved by discussion or a third reviewer $(\mathrm{RB})$.

\section{Outcomes of interest}

The interventions were compared for their effect on several outcomes relevant to patients: maternal and perinatal mortality, birth injuries, mode of delivery, shoulder dystocia, pre-eclampsia and eclampsia, neonatal hypoglycaemia, hyperbilirubinaemia and other metabolic disturbances needing an intervention, respiratory distress needing respiration, admission to neonatal intensive care, length of hospital stay, aspects of quality of life, and adverse events. Surrogate parameters considered included macrosomia or large for gestational age infants, small for gestational age infants, preterm birth, Apgar score, development of obesity in the child, gestational hypertension, and development of type 2 diabetes later in the woman's life.

\section{Statistical analysis}

When clinically and statistically appropriate, we combined results from single studies by meta-analysis using a random effects model based on the method of DerSimonian and Laird. ${ }^{11}$ The effects measure was the odds ratio. In the case of rare events $(<1 \%)$ we used the Peto one step method to pool odds ratios. ${ }^{12}$ Heterogeneity between trials was assessed with $\chi^{2}$ test and the $\mathrm{I}^{2}$ statistic, which describes the percentage of the variability in effect estimates caused by heterogeneity. ${ }^{1314}$ In the case of substantial heterogeneity $(\mathrm{P}<0.2)^{15}$ no pooled estimate was provided.

The methods, the inclusion and exclusion criteria, and the outcomes of interest were described in a prepublished protocol. ${ }^{16}$ 
Table 1|Characteristics of studies included in pool A: specific treatment for gestational diabetes mellitus versus usual care. All studies took place in hospital outpatient facilities

\begin{tabular}{|c|c|c|c|c|c|c|c|}
\hline & No & Diagnosis & Intervention & $\begin{array}{l}\text { Mean }(\mathrm{SD}) \text { age } \\
\quad \text { (years) }\end{array}$ & $\begin{array}{l}\text { Mean (SD) gestation at } \\
\text { study entry (weeks) }\end{array}$ & Mean (SD) BMI & Ethnicity (\%) \\
\hline \multicolumn{8}{|c|}{ Bonomo $2005^{17}$ (Italy) } \\
\hline Intervention & 150 & \multirow{2}{*}{$\begin{array}{l}2 \text { steps: risk factors present, } \\
\text { positive on } 50 \mathrm{~g} \text { glucose challenge*; } \\
\text { negative on } 100 \mathrm{~g} \text { oral glucose } \\
\text { tolerance test } †\end{array}$} & Diet & $31(5)$ & NA & $23(4)$ & All white \\
\hline Control & 150 & & Usual care & $31(5)$ & NA & $23(5)$ & All white \\
\hline \multicolumn{8}{|c|}{ Crowther $2005^{18-20}$ (Australia) } \\
\hline Intervention & 490 & \multirow{2}{*}{$\begin{array}{l}2 \text { steps: risk factors present or } \\
\text { positive result on } 50 \text { g glucose } \\
\text { challenge*; positive result on } 75 \mathrm{~g} \\
\text { oral glucose tolerance test§ }\end{array}$} & Diet/insulin & $31(5)$ & $29(28-30) \ddagger$ & $27(23-31) \ddagger$ & White 73 , Asian 19 , other 9 \\
\hline Control & 510 & & Usual care & $30(6)$ & $29(28-30) \ddagger$ & $26(23-31) \ddagger$ & White 78 , Asian 14 , other 8 \\
\hline \multicolumn{8}{|c|}{ Landon $2009^{21}$ (USA) } \\
\hline Intervention & 485 & \multirow{2}{*}{$\begin{array}{l}2 \text { steps: positive on } 50 \mathrm{~g} \text { glucose } \\
\text { challenge, positive on } 100 \mathrm{~g} \text { oral } \\
\text { glucose tolerance test } \uparrow\end{array}$} & Diet/insulin & $29(6)$ & $29(2)$ & $30(5)$ & $\begin{array}{l}\text { White } 25 \text {, Latin-American } 58 \text {, } \\
\text { Afro-American } 12 \text {, Asian } 5 \text {, other } 1\end{array}$ \\
\hline Control & 473 & & Usual care & $29(6)$ & $29(2)$ & $30(5)$ & $\begin{array}{l}\text { White } 25 \text {, Latin-American } 56 \text {, } \\
\text { Afro-American } 11 \text {, Asian } 6 \text {, other } 2\end{array}$ \\
\hline \multicolumn{8}{|c|}{ Langer $1989^{22}$ (USA) } \\
\hline Intervention & 63 & \multirow{2}{*}{$\begin{array}{l}2 \text { steps: positive on } 50 \mathrm{~g} \text { glucose } \\
\text { challenge }{ }^{\star \star} \text {, positive on } 100 \mathrm{~g} \text { oral } \\
\text { glucose tolerance test†† }\end{array}$} & Diet/insulin & $31(5)$ & $31(3)$ & NAł‡ & $\begin{array}{l}\text { White 36, Latin-American 33, } \\
\text { Afro-American } 30\end{array}$ \\
\hline Control & 63 & & Usual care & $28(6)$ & $31(3)$ & NAł‡ & $\begin{array}{l}\text { White 33, Latin-American 33, } \\
\text { Afro-American } 33\end{array}$ \\
\hline \multicolumn{8}{|c|}{ O'Sullivan $1966^{23}$ (USA) } \\
\hline Intervention & 307 & $\begin{array}{l}2 \text { steps: risk factors present or } \\
\text { positive on } 50 \mathrm{~g} \text { glucose }\end{array}$ & $\begin{array}{l}\text { Diet and } \\
\text { insulin }\end{array}$ & $30(N A)$ & NA & NA & NA \\
\hline Control & 308 & $\begin{array}{l}\text { challenge }^{\star \star} \text {, positive on } 100 \mathrm{~g} \text { oral } \\
\text { glucose tolerance testTा }\end{array}$ & Usual care & 31 (NA) & NA & NA & NA \\
\hline
\end{tabular}

$\mathrm{BMI}=$ body mass index; $\mathrm{NA}=$ not applicable/not available.

*Positive if blood glucose $\geq 7.8 \mathrm{mmol} / \mathrm{l}$ one hour after $50 \mathrm{~g}$ glucose challenge.

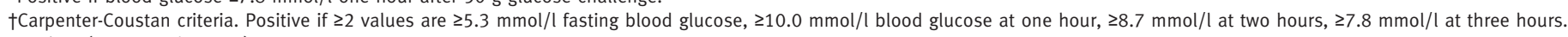
$\ddagger$ Median (interquartile range).

§WHO criteria. Positive if fasting blood glucose $<7.8 \mathrm{mmol} / \mathrm{l}$ and blood glucose $7.8-11.0 \mathrm{mmol} / \mathrm{l}$ at two hours (from $1998 \geq 7.0 \mathrm{mmol} / \mathrm{l}$ and/or $7.8-11.0 \mathrm{mmol} / \mathrm{l}$, respectively).

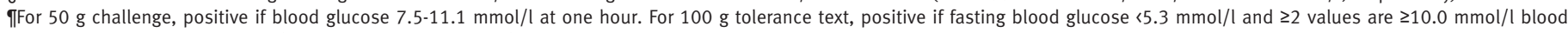

glucose at one hour, $\geq 8.6 \mathrm{mmol} / \mathrm{l}$ at two hours, $\geq 7.8 \mathrm{mmol} / \mathrm{l}$ at three hours.

** Positive if plasma glucose $>7.2 \mathrm{mmol} / \mathrm{l}$ one hour after $50 \mathrm{~g}$ glucose challenge.

††NDDG criteria. Positive if $\geq 2$ values $\geq 5.8 \mathrm{mmol} / \mathrm{l}$ fasting blood glucose, $\geq 10.6 \mathrm{mmol} / \mathrm{l}$ blood glucose at one hour, $\geq 9.2 \mathrm{mmol} / \mathrm{l}$ at two hours, $\geq 8.1 \mathrm{mmol} / \mathrm{l}$ at three hours.

$\$ \$ 38 \%$ of women in intervention group and $41 \%$ of women in control group had BMI $\geq 27$.

$\S \S$ Positive if $\geq 2$ values $\geq 6.1 \mathrm{mmol} / \mathrm{l}$ fasting blood glucose, $\geq 9.4 \mathrm{mmol} / \mathrm{l}$ blood glucose at one hour, $\geq 6.6 \mathrm{mmol} / \mathrm{l}$ at two hours, $\geq 6.1 \mathrm{mmol} / \mathrm{l}$ at three hours.

TाTPositive if $\geq 2$ values $\geq 6.1 \mathrm{mmol} / \mathrm{l}$ fasting blood glucose, $\geq 9,4 \mathrm{mmol} / \mathrm{l}$ blood glucose at one hour, $\geq 6,7 \mathrm{mmol} / \mathrm{l}$ at two hours, $\geq 6,1 \mathrm{mmol} / \mathrm{l}$ at three hours.

\section{RESULTS}

Figure 1 shows the number of trials identified and included with reasons for exclusion. The identified studies were allocated to one of two study pools based on the control treatment. Pool A contained all randomised trials of specific treatment for gestational diabetes mellitus compared with usual care. Pool B contained all randomised trials that compared specific treatments of different intensities. The comparison with usual care enabled direct inferences and effect sizes to be drawn. Pool B allowed for indirect conclusions, including the evaluation of dose-response relations.

\section{Pool A}

Five randomised trials matched the inclusion criteria for specific treatment for gestational diabetes compared with usual care (table 1). ${ }^{17-23}$ The trials were published from 1966 to 2009 and included 2999 women.

In the intervention groups all pregnant women measured their own glucose concentrations and were treated with diet alone or additional insulin treatment if blood glucose concentrations exceeded prespecified targets. All studies used a two step approach with a $50 \mathrm{~g}$ glucose challenge test or check of risk factors, or both, and a subsequent $75 \mathrm{~g}$ or $100 \mathrm{~g}$ oral glucose tolerance test. Bonomo et al included women with a positive result on the glucose challenge test but a negative result to the oral glucose tolerance test ${ }^{17}$; all other studies required a positive glucose challenge test and a positive oral glucose tolerance test for inclusion. Table 1 shows further details of study characteristics.

\section{Pool B}

Fourteen studies that compared different intensities of specific treatments fulfilled the inclusion criteria. ${ }^{24-43}$ We excluded the study by Yang et $\mathrm{al}^{4243}$ because discrepancies between publications meant that data interpretation was impossible. This left 13 trials to include in the different meta-analyses. Table 2 gives details of the diagnosis and treatment in these studies and further details on study characteristics.

\section{Bias}

In pool A the risk for bias was judged to be low for Crowther et $\mathrm{al}^{19}$ and Landon et $\mathrm{al}^{21}$ and high for the three remaining trials (table 3 ). In pool B, the risk for bias was judged to be low in two studies, ${ }^{37} 39$ and high for the remaining trials (table 3 ). 


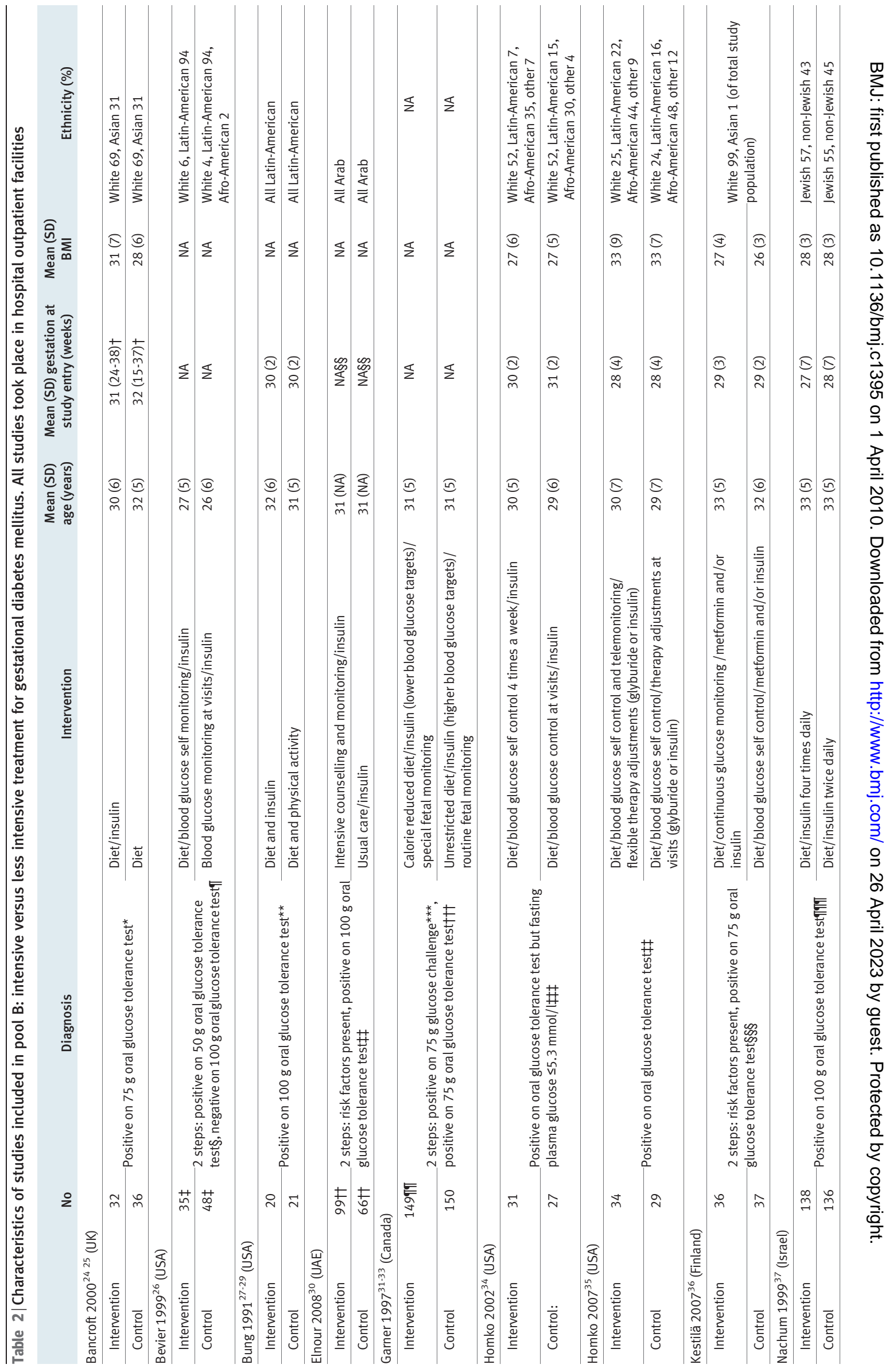




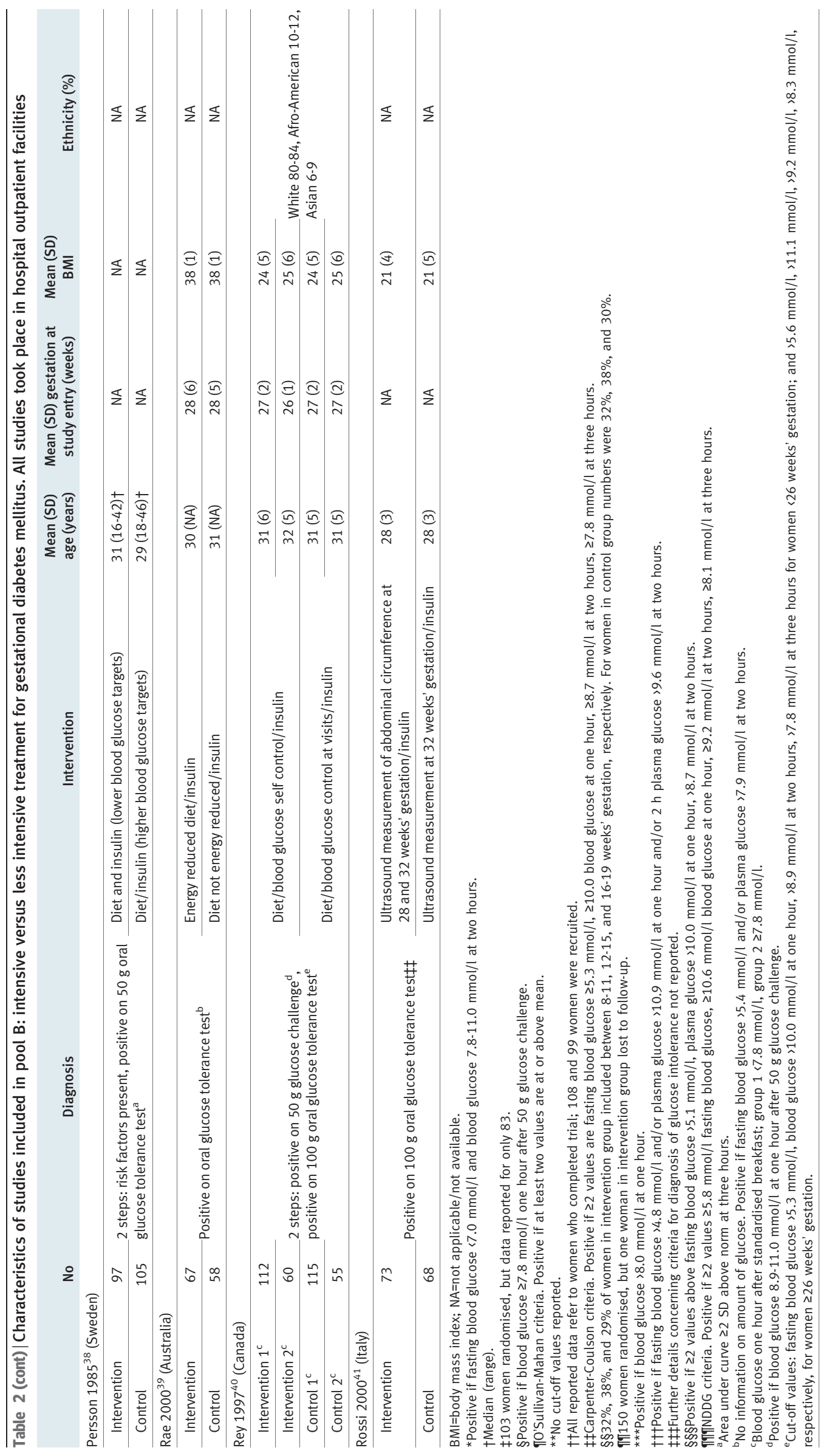

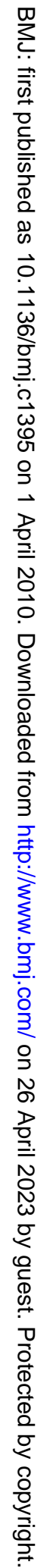


Table $3 \mid$ Risk of bias in included trials of treatment for gestational diabetes mellitus

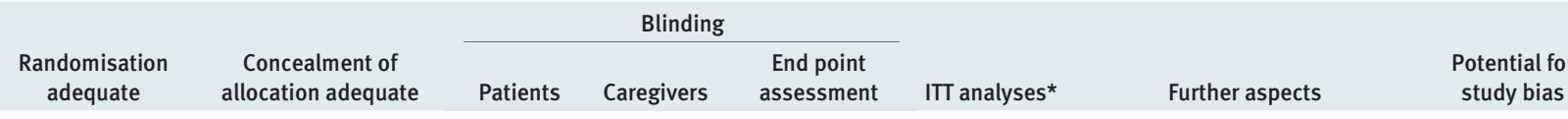

Study pool A: specific treatment $v$ usual care

\begin{tabular}{|c|c|c|c|c|c|c|c|c|}
\hline Bonomo $2005^{17}$ & Unclear & Unclear & No & No & Unclear & No & - & High \\
\hline Crowther $2005^{18-20}$ & Yes & Yes & Yes/no† & Yes/no† & Unclear & Yes & - & Low \\
\hline Landon $2009^{21}$ & Yes & Yes & Yes/not & Yes/not & Yes/unclear & No & - & Low \\
\hline Langer $1989^{22}$ & Unclear & Unclear & No & No & Unclear & Yes & - & High \\
\hline O'Sullivan $1966^{23}$ & Unclear & Unclear & No & No & Unclear & Yes & Patient flow not transparent & High \\
\hline \multicolumn{9}{|c|}{ Study pool B: intensive $v$ less intensive treatment } \\
\hline Bancroft $2000^{24,25}$ & Yes & Yes & No & Yes & Unclear & Yes & $\begin{array}{l}\text { Patient flow not transparent. } \\
\text { Pilot study aimed at feasibility }\end{array}$ & High \\
\hline Bevier $1999^{26}$ & Unclear & Unclear & No & No & Unclear & No & Patient flow not transparent & High \\
\hline Bung $1991^{27-29}$ & Unclear & Unclear & No & No & Unclear & No & Patient flow not transparent & High \\
\hline Elnour $2008^{30}$ & Unclear & Unclear & No & No & Unclear & No & - & High \\
\hline Garner $1997^{31-33}$ & Yes & Unclear & No & Unclear & Unclear & Yes & Pilot study aimed at feasibility & High \\
\hline Homko $2002^{34}$ & Unclear & Unclear & No & No & Unclear & Yes & Patient flow not transparent & High \\
\hline Homko $2007^{35}$ & Unclear & Unclear & No & No & Unclear & No & Patient flow not transparent & High \\
\hline Kestilä $2007^{36}$ & Unclear & Unclear & No & No & Unclear & Yes & Patient flow not transparent & High \\
\hline Nachum $1999^{37}$ & Yes & Yes & No & No & No & Yes & - & Low \\
\hline Persson $1985^{38}$ & Unclear & Unclear & No & No & Unclear & Unclear & - & High \\
\hline Rae $2000^{39}$ & Unclear & Yes & Yes & Yes & Unclear & Unclear & Patient flow not transparent & Low \\
\hline Rey $1997^{40}$ & Yes & Unclear & No & No & Unclear & Yes & Patient flow not transparent & High \\
\hline Rossi $2000^{41}$ & Unclear & Unclear & No & Yes & Yes & No & Patient flow not transparent & High \\
\hline
\end{tabular}

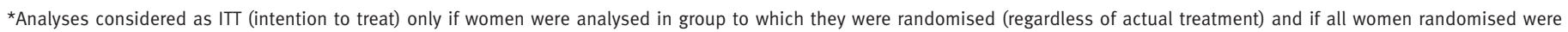
included in analyses.

†Women and care givers in control group but not in intervention group were blinded for results of glucose challenge test and oral glucose tolerance test.

Specific treatment versus usual care: pool A

None of the trial specifically reported on maternal deaths. There were no significant differences between specific treatment and usual care in three ${ }^{171922}$ of the four studies that reported caesarean sections (table 4). Landon et al reported a significantly lower rate of caesarean sections with specific interventions. ${ }^{21}$ The metaanalysis, which included results from all four trials, did not show a significant difference, the odds ratio being 0.86 (95\% confidence interval 0.72 to 1.02 ) (fig 2). In the study of Landon et al 12 of 476 women $(2.5 \%)$ in the intervention group and 25 of 455 women $(5.5 \%)$ in the usual care group developed pre-eclampsia $(\mathrm{P}=0.02) .{ }^{21}$ Only Crowther et $\mathrm{al}^{19}$ and Landon et $\mathrm{al}^{21}$ reported on shoulder dystocia. The pooled analysis of both studies yielded a significant difference in favour of the intervention group (0.40, 0.21 to 0.75 ; fig 2$)$.

Only one trial reported on long term complications in the mother. O'Sullivan et al reported that 35\% of women in the specific treatment and $36 \%$ of women in the usual care group developed diabetes within 16 years after delivery (table 4). ${ }^{23}$ The difference was not significant. Other long term outcomes were not reported.

Three trials provided information on perinatal or neonatal mortality. ${ }^{192123}$ While there were no neonatal or perinatal deaths reported by Landon et $\mathrm{al}^{21}$ and in the intervention group in Crowther et al, ${ }^{19}$ five such events occurred in the control group of Crowther et $\mathrm{al}^{19}$ (table 5). This difference was not significant $(\mathrm{P}=0.07)$. In the study by $\mathrm{O}$ 'Sullivan et $\mathrm{al},{ }^{23}$ perinatal mortality was $4 \%$ in the intervention group and $5 \%$ in the conrol group (table 5). Again the difference was not significant. Results were not pooled because of high heterogeneity $\left(\mathrm{P}=0.099 ; \mathrm{I}^{2}=63.3 \%\right)$ (fig 3).

The number of large for gestational age infants was significantly lower in the treatment groups than in the usual care groups in four studies (table 5). ${ }^{17192122}$ Data from these studies were also included in a meta-analysis, which showed a significant reduction with specific treatment for gestational diabetes mellitus $(0.48,0.38$ to 0.62 ; fig 3 ). Macrosomia was also significantly reduced in groups with specific treatment $(0.38,0.30$ to 0.49 ). The number of small for gestational age infants did not differ significantly between groups (table 5 and fig 3 ).

Results from Crowther et $\mathrm{al}^{19}$ and Landon et $\mathrm{al}^{21}$ on the number of babies with neonatal hypoglycaemia treated with a glucose infusion could not be pooled in meta-analyses because of heterogeneity $(\mathrm{P}=0.125$; $\mathrm{I}^{2}=57.6 \%$ ). While in the study of Crowther et $\mathrm{al}^{19}$ these events occurred more often in the intervention group, in Landon et $\mathrm{al}^{21}$ they occurred less often (fig 3).

The meta-analysis on birth trauma, which included data from Crowther et al ${ }^{19}$ and Landon et al, ${ }^{21}$ showed a lower number of such events in the intervention group than in the usual care group, but the difference was not significant $(0.39,0.13$ to $1.15 ; \mathrm{P}=0.088$; fig 3$)$. Three trials provided data on the number of newborns requiring admission to a neonatal intensive care unit. ${ }^{172122}$ In each of these studies, a smaller proportion of infants from mothers in the specific treatment group had to be 
Table $4 \mid$ Maternal outcomes in study pool A: specific treatment versus usual care

\begin{tabular}{|c|c|c|c|c|c|c|c|c|c|c|}
\hline & \multicolumn{2}{|c|}{$\begin{array}{l}\text { Maternal } \\
\text { mortality* }\end{array}$} & \multicolumn{2}{|c|}{$\begin{array}{l}\text { Shoulder } \\
\text { dystocia }\end{array}$} & \multicolumn{2}{|c|}{$\begin{array}{l}\text { Caesarean } \\
\text { section }\end{array}$} & \multicolumn{2}{|c|}{ Pre-eclampsia } & \multicolumn{2}{|c|}{$\begin{array}{c}\text { Diabetes mellitus } \\
\text { later in life }\end{array}$} \\
\hline & No (\%) & $P$ value & No (\%) & P value & No (\%) & $P$ value & No (\%) & P value & No (\%) & $P$ value \\
\hline \multicolumn{11}{|l|}{ Bonomo $2005^{17}$} \\
\hline Intervention & NA & \multirow{2}{*}{ NA } & NA & \multirow{2}{*}{ NA } & $44(29)$ & \multirow{2}{*}{ NA } & NA & \multirow{2}{*}{ NA } & NA & \multirow{2}{*}{ NA } \\
\hline Control & NA & & NA & & $42(28)$ & & NA & & NA & \\
\hline \multicolumn{11}{|c|}{ Crowther $2005^{18-20}$} \\
\hline Intervention & $0(0)$ & \multirow{2}{*}{ NA } & 7 (1) & \multirow{2}{*}{0.08} & $152(31)$ & \multirow{2}{*}{0.73} & $\mathrm{NA} \dagger$ & \multirow{2}{*}{ NA } & NA & \multirow{2}{*}{ NA } \\
\hline Control & $0(0)$ & & $16(3)$ & & $164(32)$ & & $\mathrm{NA} \dagger$ & & NA & \\
\hline \multicolumn{11}{|l|}{ Landon $2009^{21}$} \\
\hline Intervention $\ddagger$ & NA & \multirow{2}{*}{ NA } & $7(2)$ & \multirow{2}{*}{0.02} & $128(27)$ & \multirow{2}{*}{0.02} & $12(3)$ & \multirow{2}{*}{0.02} & NA & \multirow{2}{*}{ NA } \\
\hline Controlf & NA & & $18(4)$ & & $154(34)$ & & $25(6)$ & & NA & \\
\hline \multicolumn{11}{|l|}{ Langer $1989^{22}$} \\
\hline Intervention & $0(0)$ & \multirow{2}{*}{ NA } & NA & \multirow{2}{*}{ NA } & $9(15)$ & \multirow{2}{*}{ NA } & NA & \multirow{2}{*}{ NA } & NA & \multirow{2}{*}{ NA } \\
\hline Control & $0(0)$ & & NA & & $11(17)$ & & NA & & NA & \\
\hline \multicolumn{11}{|l|}{ O'Sullivan $1966^{23}$} \\
\hline Intervention & $0(0)$ & \multirow{2}{*}{ NA } & NA & \multirow{2}{*}{ NA } & NA & \multirow{2}{*}{ NA } & NA & \multirow{2}{*}{ NA } & $107(35)$ & \multirow{2}{*}{ NS } \\
\hline Control & $0(0)$ & & NA & & NA & & NA & & $110(36)$ & \\
\hline
\end{tabular}

NA=not applicable/not available; NS=not significant.

*Assumed to be zero in those studies that included all randomised women in analyses but not specifically reported.

$\dagger$ Pre-eclampsia defined as blood pressure $\geq 140 / 90 \mathrm{~mm} \mathrm{Hg}$ on two occasions more than four hours apart; corresponds to pregnancy induced

hypertension rather than pre-eclampsia.

$\ddagger n=476$ in intervention group, 455 in control group.

transferred to an intensive care unit (table 5), but in none was the difference significant. For this outcome, we performed a pooled analysis and found that the lower risk for babies of mothers with specific treatment was not significant $(0.73,0.50$ to $1.06 ; \mathrm{P}=0.098$; fig 3$)$.

Crowther et al reported a combined end point, which consisted of any of perinatal death, shoulder dystocia, bone fracture, or nerve palsy. ${ }^{19}$ Such complications were seen in $1 \%$ of all babies from mothers in the intervention group and $4 \%$ of babies born to mothers in the usual care group $(\mathrm{P}=0.01$ for difference $)$. Landon et al also reported a composite neonatal outcome, including stillbirth, neonatal death, hypoglycaemia, hyperbilirubinaemia, raised $\mathrm{C}$ peptide concentration in cord blood, and birth trauma, as the designated primary end point. ${ }^{21}$ This outcome occurred in $32 \%$ of babies from mothers with specific treatment and $37 \%$ of babies from mothers in the usual care group $(\mathrm{P}=0.14$ for difference).

No adverse effects from treatment were reported. No trials reported on long term effects in the children.

\section{Intensive $v$ less intensive specific treatment: pool B}

Tables 6 and 7 show results from individual studies. None of the trials reported any maternal deaths. More intensive treatment had no significant effects on the incidence of caesarean section $(1.04,0.80$ to 1.34 ; fig 4). Five trials provided information on preeclampsia. ${ }^{2630343539}$ Because of the high heterogeneity $\left(\mathrm{P}=0.116 ; \mathrm{I}^{2}=46.1 \%\right)$ we did not perform a combined analysis (fig 4). The difference between the comparison groups reached significance in only one trial ${ }^{30}$ (table 6). The pooled estimate showed a significant reduction in shoulder dystocia in women with intensified treatment (0.31, 0.14 to 0.70 ; fig 4$)$.
Only one trial provided information on the development of diabetes mellitus later in life. ${ }^{2425}$ While no women in the intensified treatment group developed diabetes, this was the case for two women $(7 \%)$ in the control group. The difference was not significant. It remains unclear how long after giving birth the women were tested. As for adverse events with intensified treatment of gestational diabetes, only two studies reported on maternal hypoglycaemia. In the trial by Bung et al no woman experienced a hypoglycaemic episode. ${ }^{27-29}$ In the study by Nachum et al, one woman $(0.7 \%)$ in each of the comparison groups experienced serious hypoglycaemia. ${ }^{37} \mathrm{We}$ found no information on possible adverse effects of false positive or false negative test results and labelling and on behavioural changes postpartum.

Eight studies reported on perinatal mortality, ${ }^{242531-3840}$ with four perinatal deaths in 1380 pregnant women. The pooled estimate did not show a significant difference between intensified and less intensified treatment (0.96, 0.19 to 4.79 ; fig 5).

We carried out a meta-analysis for the results on macrosomia and on babies with a birth weight at or above the 90th centile (large for gestational age) but could not give a pooled estimate because of the high degree of heterogeneity $\left(\mathrm{P}=0.166, \mathrm{I}^{2}=31.5 \%\right.$ for macrosomia; $\mathrm{P}=0.021, \mathrm{I}^{2}=52.4 \%$ for large for gestational age) (fig 5).

The risk of babies with birth weights at or below the 10th centile (small for gestational age) was not significantly different between the groups $(0.85,0.50$ to 1.44 ; fig 5). Information on birth weight was available from all but two studies ${ }^{3041}$; in only one study ${ }^{26}$ was it significantly lower in babies from women receiving intensified treatment (table 7). 


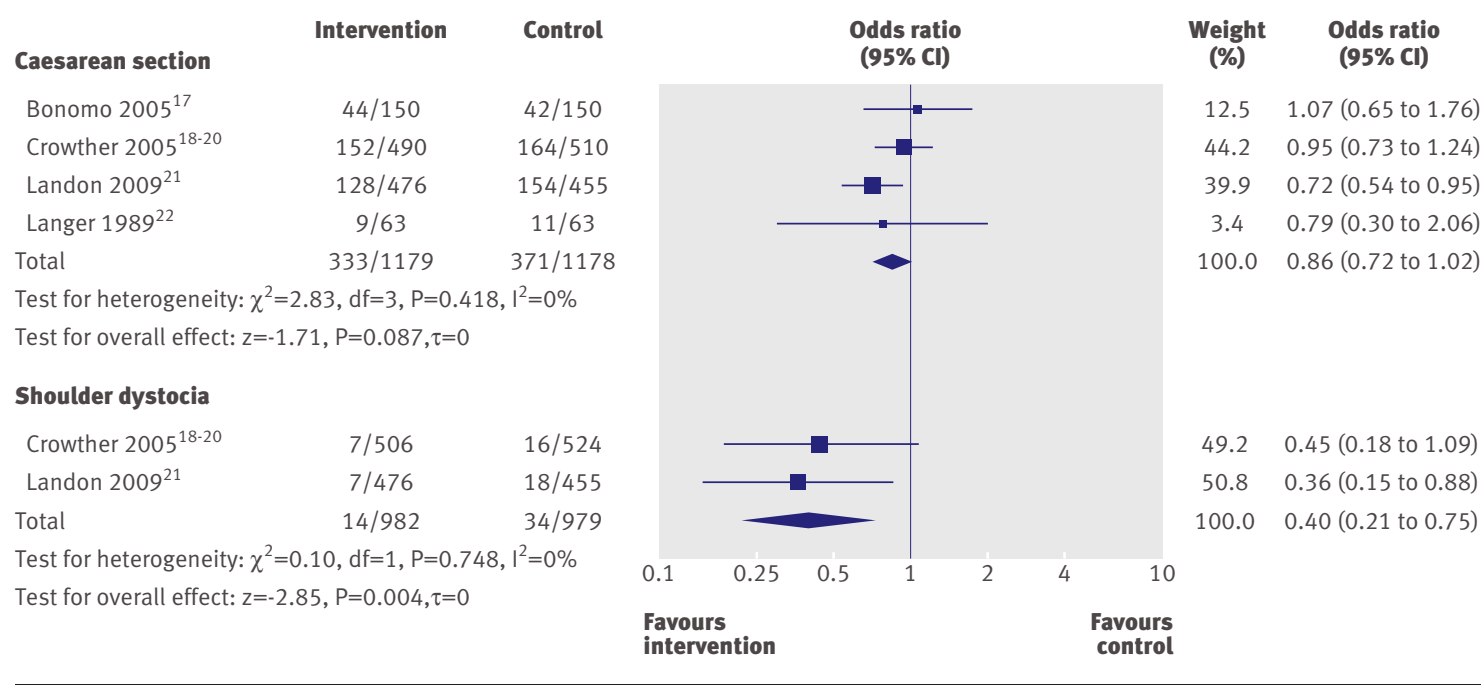

Fig 2 | Maternal outcomes in pool A (DerSimonian and Laird random effects model)

Three trials reported results on birth trauma (nerve palsy and bone fracture)..$^{31-3437}$ A pooled analysis showed no significant difference between the effects of intensified and less intensified treatment $(0.71,0.16$ to 3.17 ; fig 5). We found no information on neonatal hypoglycaemia necessitating glucose infusion or on the necessity of breathing support in babies with respiratory distress syndrome. Insufficient data on possible long term effects for the children were available.

Adverse effects from treatment were not reported. Table 7 gives results on gestational age at delivery. None of the studies that reported on this outcome found significant differences between the comparison groups.

\section{DISCUSSION}

\section{Main findings}

In this systematic review we found that shoulder dystocia is reduced significantly in women treated for gestational diabetes. Women who received specific treatment for gestational diabetes also had fewer macrosomic babies or babies with a birth weight at or above the 90th centile. Specific treatment had no significant effects on the number of babies small for gestational age or on perinatal or neonatal death, ${ }^{1921}$ though perinatal death was much more common in one older study, ${ }^{23}$ probably reflecting the advances in pregnancy and neonatal care from the 1960s to today.

We included data from randomised controlled trials that looked at specific treatment compared with usual care (study pool A) from five studies. Within this pool the studies by Crowther et $\mathrm{al}^{19}$ and Landon et $\mathrm{al}^{21}$ had the largest number of women included and had a low risk of bias.

Crowther et al reported a significant reduction of a combined end point consisting of perinatal death, shoulder dystocia, bone fracture, or nerve palsy associated with treatment for gestational diabetes. ${ }^{19}$ The combined end point in the study by Landon et al including various perinatal outcomes (stillbirth, neonatal death, hypoglycaemia, hyperbilirubinaemia raised concentration of $\mathrm{C}$ peptide in cord blood, and birth trauma) was not significantly different between treated and untreated women. ${ }^{21}$

All studies in pool A recruited women with gestational diabetes based on a two step strategy. In a first step women were selected by a positive result on a glucose challenge test (or risk factors). These women underwent an oral glucose tolerance test and were included in the studies if the result was positive. Bonomo et al, however, included women with a positive result on a glucose challenge test but a negative result on an oral glucose tolerance test. ${ }^{17}$

Results from randomised controlled trials that compared different intensities of treatment for gestational diabetes (study pool B) showed a significant reduction in risk for shoulder dystocia with more intense treatment. There were only four perinatal deaths in 1380 pregnancies. The reduction in macrosomia was not significant. Results from study pool B were comparable with those from pool $\mathrm{A}$ for the end points of small for gestational age and major maternal complications.

Based on the results we concluded that specific treatment for gestational diabetes, mostly consisting of treatment to lower blood glucose concentration, alone or with special obstetric care, seems to lower the risk of some perinatal or neonatal complications. We did not find sufficient data to draw any conclusions on possible long term effects of treatment for gestational diabetes in the mothers or their children.

\section{Strengths and limitations}

To our knowledge this review is the most current report on the topic and includes the recently published trial by Landon et al. ${ }^{21}$ It also benefits from a thorough search and assessment of randomised controlled trials, performance of meta-analyses on a wide range of maternal and neonatal outcomes, and the differentiation between trials investigating specific treatment for 


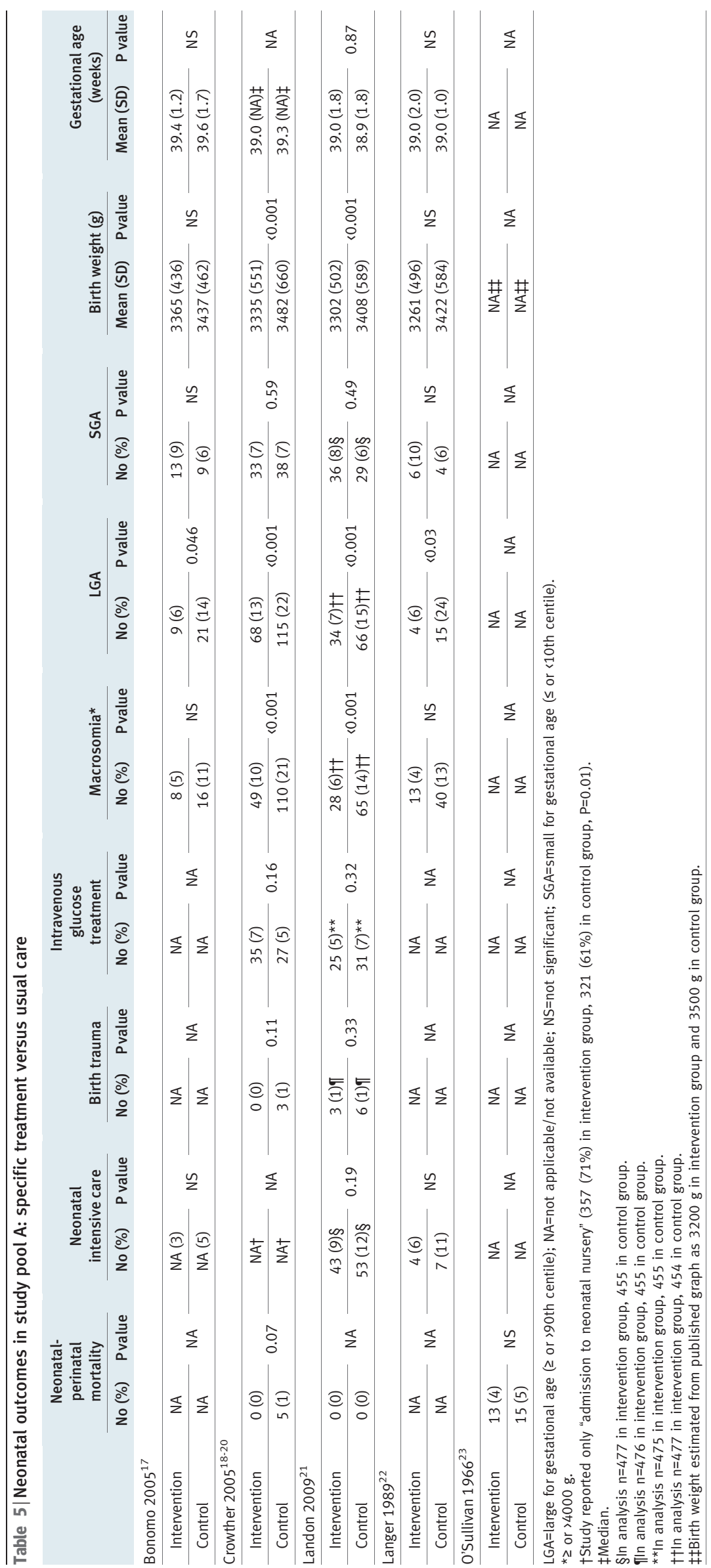

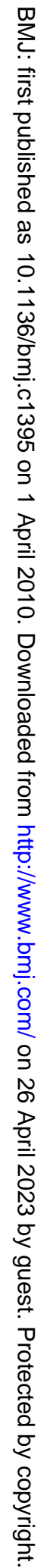




\begin{tabular}{|c|c|c|c|c|c|c|c|c|c|}
\hline \multirow{2}{*}{$\begin{array}{l}\text { Perinatal and } \\
\text { neonatal mortality } \\
\text { Crowther } 2005^{18-20}\end{array}$} & \multirow{2}{*}{$\begin{array}{c}\text { Intervention } \\
\text { 0/506 }\end{array}$} & \multirow{2}{*}{$\begin{array}{l}\text { Control } \\
\text { 5/524 }\end{array}$} & \multicolumn{5}{|c|}{$\begin{array}{l}\text { Odds ratio } \\
\text { (95\% Cl) }\end{array}$} & \multirow{2}{*}{$\begin{array}{c}\text { Weight } \\
\text { (\%) } \\
18.2\end{array}$} & \multirow{2}{*}{$\begin{array}{c}\text { Odds ratio } \\
\text { (95\% Cl) } \\
0.19(0.04 \text { to } 0.96)\end{array}$} \\
\hline & & & 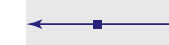 & & & & & & \\
\hline Landon $2009^{21}$ & $0 / 477$ & $0 / 455$ & & & & & & - & - \\
\hline O’Sullivan $1966^{23}$ & $13 / 307$ & $15 / 308$ & & $\longrightarrow$ & trat & & & 81.8 & $0.86(0.41$ to 1.84$)$ \\
\hline \multicolumn{10}{|c|}{ Test for heterogeneity: $\chi^{2}=2.72, \mathrm{df}=1, \mathrm{P}=0.099, \mathrm{I}^{2}=63.3 \%$} \\
\hline \multicolumn{10}{|c|}{ Large for gestational age } \\
\hline Bonomo $2005^{17}$ & $9 / 150$ & $21 / 150$ & & 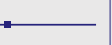 & & & & 8.9 & $0.39(0.17$ to 0.89$)$ \\
\hline Crowther $2005^{18-20}$ & $68 / 506$ & $115 / 524$ & & $\longrightarrow$ & & & & 55.2 & $0.55(0.40$ to 0.77$)$ \\
\hline Landon $2009^{21}$ & $34 / 477$ & $66 / 454$ & & $\rightarrow$ & & & & 31.4 & $0.45(0.29$ to 0.70$)$ \\
\hline Langer $1989^{22}$ & $4 / 63$ & $15 / 63$ & & & & & & 4.4 & $0.22(0.07$ to 0.70$)$ \\
\hline Total & $115 / 1196$ & $217 / 1191$ & & & & & & 100.0 & $0.48(0.38$ to 0.62$)$ \\
\hline \multicolumn{10}{|c|}{ Test for heterogeneity: $\chi^{2}=2.79, \mathrm{df}=3, \mathrm{P}=0.425, \mathrm{I}^{2}=0 \%$} \\
\hline \multicolumn{10}{|c|}{ Test for overall effect: $z=-5.85, P<0.001, \tau=0$} \\
\hline \multicolumn{10}{|l|}{ Macrosomia } \\
\hline Bonomo $2005^{17}$ & $8 / 150$ & $16 / 150$ & & & & & & 8.1 & $0.47(0.20$ to 1.14$)$ \\
\hline Crowther $2005^{18-20}$ & $49 / 506$ & $110 / 524$ & & - & & & & 47.8 & $0.40(0.28$ to 0.58$)$ \\
\hline Landon $2009^{21}$ & $28 / 477$ & $65 / 454$ & & & & & & 29.2 & $0.37(0.23$ to 0.59$)$ \\
\hline O’Sullivan $1966^{23}$ & $13 / 307$ & $40 / 308$ & & & & & & 15.0 & $0.30(0.16$ to 0.57$)$ \\
\hline Total & $98 / 1440$ & $231 / 1436$ & & & & & & 100.0 & $0.38(0.30$ to 0.49$)$ \\
\hline \multicolumn{10}{|c|}{ Test for heterogeneity: $\chi^{2}=0.91, d f=3, P=0.823, I^{2}=0 \%$} \\
\hline \multicolumn{10}{|c|}{ Test for overall effect: $z=-7.55, P<0.001, \tau=0$} \\
\hline \multicolumn{10}{|c|}{ Small for gestational age } \\
\hline Bonomo $2005^{17}$ & $13 / 150$ & $9 / 150$ & & & $\rightarrow$ & & & 12.8 & 1.49 (0.62 to 3.59$)$ \\
\hline Crowther $2005^{18-20}$ & $33 / 506$ & $38 / 524$ & & 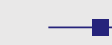 & - & & & 42.7 & $0.89(0.55$ to 1.45$)$ \\
\hline Landon $2009^{21}$ & $36 / 477$ & $29 / 455$ & & & 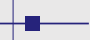 & & & 38.8 & $1.20(0.72$ to 1.99$)$ \\
\hline Langer $1989^{22}$ & $6 / 63$ & $4 / 63$ & & & - & & & 5.7 & $1.55(0.42$ to 5.79$)$ \\
\hline Total & $88 / 1196$ & $80 / 1192$ & & & - & & & 100.0 & $1.10(0.80$ to 1.51$)$ \\
\hline \multicolumn{10}{|c|}{ Test for heterogeneity: $\chi^{2}=1.54, \mathrm{df}=3, \mathrm{P}=0.672, \mathrm{I}^{2}=0 \%$} \\
\hline \multicolumn{10}{|c|}{ Test for overall effect: $z=0.61, P=0.543, \tau=0$} \\
\hline \multicolumn{10}{|c|}{ Neonatal hypoglycaemia with glucose infusion } \\
\hline Crowther $2005^{18-20}$ & $35 / 506$ & $27 / 524$ & & & & & & 51.0 & 1.37 (0.82 to 2.30$)$ \\
\hline Landon $2009^{21}$ & $25 / 475$ & $31 / 455$ & & $\longrightarrow$ & 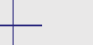 & & & 49.0 & $0.76(0.44$ to 1.31$)$ \\
\hline \multicolumn{10}{|c|}{ Test for heterogeneity: $\chi^{2}=2.36, d f=1, P=0.125, I^{2}=57.6 \%$} \\
\hline \multicolumn{10}{|l|}{ Birth trauma } \\
\hline Crowther $2005^{18-20}$ & $0 / 506$ & $3 / 524$ & $\leftarrow$ & & & & & 30.9 & $0.23(0.03$ to 1.64$)$ \\
\hline Landon $2009^{21}$ & $3 / 476$ & $6 / 455$ & & - & & & & 69.1 & $0.49(0.13$ to 1.81$)$ \\
\hline Total & $3 / 982$ & $9 / 979$ & & & & & & 100.0 & $0.39(0.13$ to 1.15$)$ \\
\hline \multicolumn{10}{|c|}{ Test for heterogeneity: $\chi^{2}=0.39, \mathrm{df}=1, \mathrm{P}=0.533, \mathrm{I}^{2}=0 \%$} \\
\hline \multicolumn{10}{|c|}{ Test for overall effect: $z=-1.71, P=0.088$} \\
\hline Neonatal intensive & & & & & & & & & \\
\hline Bonomo $2005^{17}$ & $5 / 150$ & $7 / 150$ & & & & & & 10.6 & $0.70(0.22$ to 2.27$)$ \\
\hline Landon $2009^{21}$ & $43 / 477$ & $53 / 455$ & & 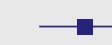 & - & & & 80.6 & 0.75 (0.49 to 1.15$)$ \\
\hline Langer $1989^{22}$ & $4 / 63$ & $7 / 63$ & & & & & & 8.8 & 0.54 (0.15 to 1.95$)$ \\
\hline Total & $52 / 690$ & $67 / 668$ & & & & & & 100.0 & 0.73 (0.50 to 1.06$)$ \\
\hline Test for heterogeneit & .23, $\mathrm{df}=2, \mathrm{P}=0$. & $I^{2}=0 \%$ & 0.25 & 0.5 & 1 & 4 & 10 & & \\
\hline Test for overall effect & 65, $P=0.098, \tau=$ & & $\begin{array}{l}\text { Favours } \\
\text { intervention }\end{array}$ & & & & $\begin{array}{c}\text { Favours } \\
\text { control }\end{array}$ & & \\
\hline
\end{tabular}

gestational diabetes and usual care and trials studying different intensities of treatment.

The evidence on beneficial effects of treatment, however, is still unstable. Although we identified many studies investigating the effects of treatment, effects on major end points important to patients remain uncertain. These complications are infrequent and information is available from only a few of the included studies.

Two studies ${ }^{1921}$ dominated the results, so the limitations of these trials must be considered. In Crowther et 
Table $6 \mid$ Maternal outcomes in study pool B: intensive versus less intensive treatment

\begin{tabular}{|c|c|c|c|c|c|c|c|c|c|c|}
\hline & \multicolumn{2}{|c|}{$\begin{array}{l}\text { Maternal } \\
\text { mortality* }\end{array}$} & \multicolumn{2}{|c|}{$\begin{array}{l}\text { Shoulder } \\
\text { dystocia }\end{array}$} & \multicolumn{2}{|c|}{$\begin{array}{l}\text { Caesarean } \\
\text { section }\end{array}$} & \multicolumn{2}{|c|}{ Pre-eclampsia } & \multicolumn{2}{|c|}{$\begin{array}{l}\text { Diabetes mellitus } \\
\text { later in life }\end{array}$} \\
\hline & No (\%) & $P$ value & No (\%) & $P$ value & No (\%) & $P$ value & No (\%) & $P$ value & No (\%) & $P$ value \\
\hline \multicolumn{11}{|l|}{ Bancroft $2000^{2425}$} \\
\hline Intervention & $0(0)$ & \multirow{2}{*}{ NA } & $0(0)$ & \multirow{2}{*}{ NA } & $10(31)$ & \multirow{2}{*}{ NS } & NA & \multirow{2}{*}{ NA } & $0(0) \dagger$ & \multirow{2}{*}{ NS } \\
\hline Control & $0(0)$ & & $1(3)$ & & $11(31)$ & & NA & & $2(7) \dagger$ & \\
\hline \multicolumn{11}{|l|}{ Bevier $1999^{26}$} \\
\hline Intervention & NA & \multirow{2}{*}{ NA } & $1(3)$ & \multirow{2}{*}{ NS } & $5(14)$ & \multirow{2}{*}{ NA } & $2(6)$ & \multirow{2}{*}{ NS } & NA & \multirow{2}{*}{ NA } \\
\hline Control & NA & & $2(5)$ & & $12(25)$ & & $1(2)$ & & NA & \\
\hline \multicolumn{11}{|l|}{ Bung $1991^{27-29}$} \\
\hline Intervention & NA & \multirow{2}{*}{ NA } & NA & \multirow{2}{*}{ NA } & $3(18)$ & \multirow{2}{*}{ NA } & NA & \multirow{2}{*}{ NA } & NA & \\
\hline Control & NA & & NA & & $2(12)$ & & NA & & NA & NA \\
\hline Elnour $2008^{30}$ & & & & & & & & & & \\
\hline Intervention & NA & & $2(2)$ & & $7(7)$ & 000 & $5(5)$ & 01 & NA & No \\
\hline Control & NA & $\mathrm{INA}$ & $6(9)$ & 0.001 & $12(18)$ & 0.028 & $11(17)$ & 0.014 & NA & TNA \\
\hline Garner $1997^{31-33}$ & & & & & & & & & & \\
\hline Intervention & NA & & NA & & NA (20) & 089 & NA & NA & NA & No \\
\hline Control & NA & NA & NA & NA & NA (19) & 0.861 & NA & $\mathrm{NA}$ & NA & $\mathrm{NA} A$ \\
\hline Homko $2002^{34}$ & & & & & & & & & & \\
\hline Intervention & NA & & NA & & $11(36)$ & N & $0(0)$ & & NA & \\
\hline Control & NA & $\mathrm{NA}$ & NA & $\mathrm{NA}$ & 5 (19) & NS & $2(7)$ & NS & NA & $\mathrm{NA}$ \\
\hline Homko $2007^{35}$ & & & & & & & & & & \\
\hline Intervention & NA & NA & NA & 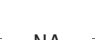 & $22(69)$ & 0 & $9(28) \ddagger$ & NC & NA & No \\
\hline Control & NA & NA & NA & NA & $10(40)$ & 0.53 & $5(20) \ddagger$ & NS & NA & NA \\
\hline Kestilä $2007^{36}$ & & & & & & & & & & \\
\hline Intervention & $0(0)$ & 10 & NA & 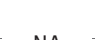 & NA (22) & & NA & & NA & 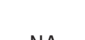 \\
\hline Control & $0(0)$ & NA & NA & NA & NA (22) & 0.47 & NA & INS & NA & NA \\
\hline Nachum $1999^{37}$ & & & & & & & & & & \\
\hline Intervention & $0(0)$ & & NA & & $39(28)$ & & NA & & NA & \\
\hline Control & $0(0)$ & NA & NA & NA & $38(28)$ & NS & NA & $N A$ & NA & NA \\
\hline Persson $1985^{38}$ & & & & & & & & & & \\
\hline Intervention & $0(0)$ & & NA & & NA & & NA & & NA & \\
\hline Control & $0(0)$ & NA & NA & NA & NA & NA & NA & NS & NA & NA \\
\hline Rae $2000^{39}$ & & & & & & & & & & \\
\hline Intervention & NA & & $0(0)$ & 0005 & $26(41)$ & No & $14(22)$ & 0070 & NA & No \\
\hline Control & NA & $\mathrm{NA} A$ & $3(6)$ & 0.095 & $19(35)$ & $\mathrm{NAA}$ & $13(22)$ & 0.838 & NA & $\mathrm{NA} A$ \\
\hline Rey $1997^{40}$ & & & & & & & & & & \\
\hline Intervention $1 \S$ & NA & & $1(1)$ & N & $24(21)$ & $\mathrm{C}_{0}$ & NA & 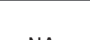 & NA & 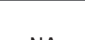 \\
\hline Intervention $2 \S$ & NA & NA & $0(0)$ & NS & $26(23)$ & NA & NA & NA & NA & NA \\
\hline Control 1§ & NA & & $0(0)$ & & $14(24)$ & & NA & & NA & \\
\hline Control $2 \S$ & NA & NA & $4(7)$ & 0.05 & $14(25)$ & NA & NA & NA & NA & NA \\
\hline Rossi $2000^{41}$ & & & & & & & & & & \\
\hline Intervention & NA & & NA & & $17(23)$ & & NA & & NA & \\
\hline Control & NA & NA & NA & NA & $17(25)$ & NS & NA & $\mathrm{NA}$ & NA & NA \\
\hline
\end{tabular}

NA=not applicable/not available; NS=not significant.

*Assumed to be zero in those studies that included all randomised women in analyses but not specifically reported.

†Two additional women (7\%) in intervention group and three in control group (11\%) developed glucose intolerance P=NS. Analyses included only 56 of 68 randomised women.

$\ddagger$ Sum of pregnancy associated hypertension and pre-eclampsia.

§Blood glucose one hour after standardised breakfast; group $1<7.8 \mathrm{mmol} / \mathrm{l}$, group $2 \geq 7.8 \mathrm{mmol} / \mathrm{l}$.

$\mathrm{al}^{19}$ women in the control group had gestational diabetes but they and their perinatal care providers were told that they did not have it. Women in the intervention group were not blinded. This can be seen as a possible bias leading to undertreatment in the control group or overtreatment in the intervention group (or both). In usual care "telling" is part of the intervention, so this is likely to reflect what happens when labelling a pregnant woman with the diagnosis of gestational diabetes. Induction of labour and transfer of newborns to a neonatal nursery were higher in the intervention group. We regarded these interventions as part of the specific care for gestational diabetes. It is unclear whether these interventions were responsible for the improved neonatal outcomes or whether they were overtreatment (and a harm) induced by labelling. 


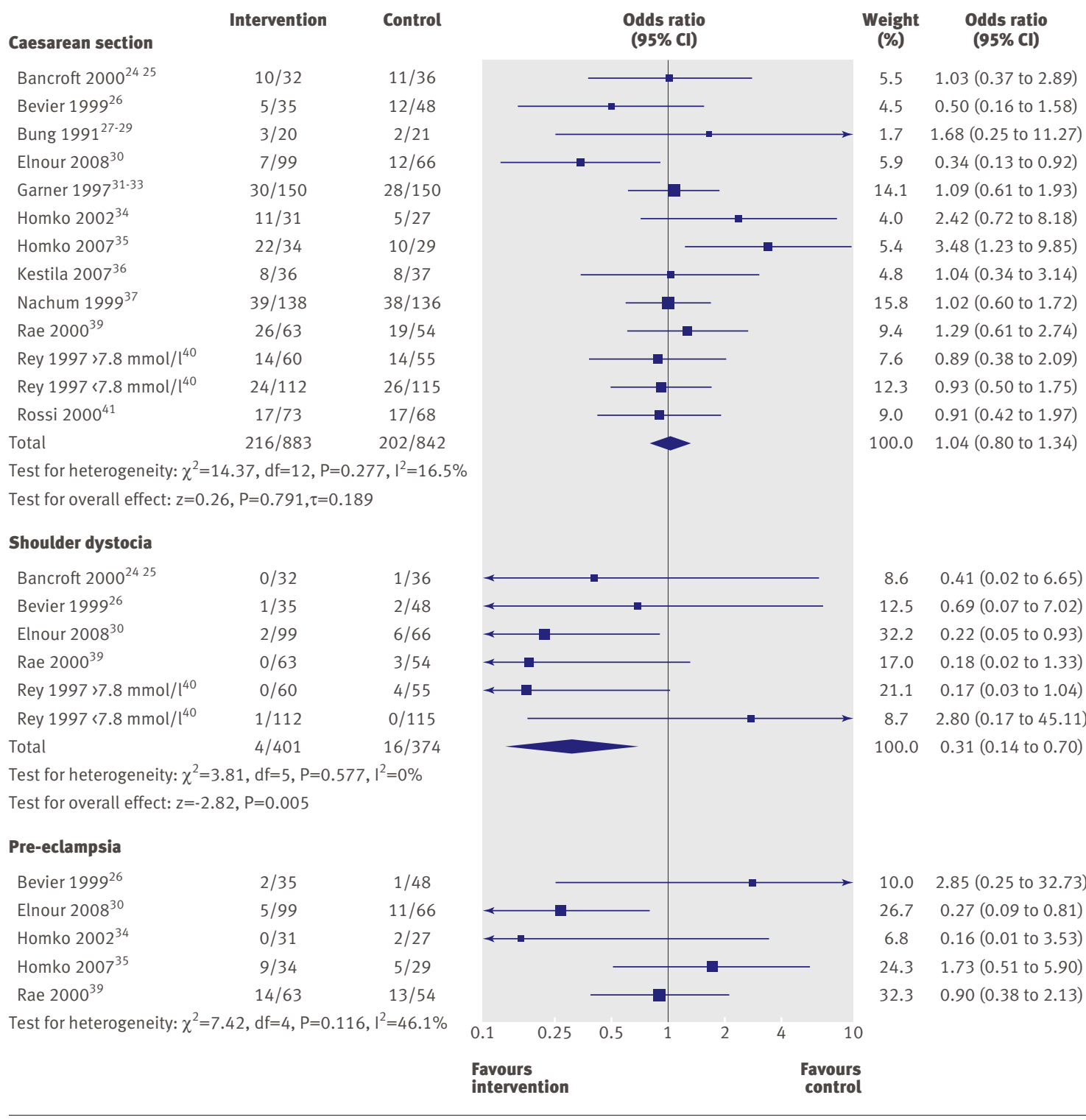

Fig 4 | Maternal outcomes in pool B (DerSimonian and Laird random effects model, except for shoulder dystocia, which uses Peto fixed effects model)

A second limitation in that study is the choice of a combined end point. ${ }^{19}$ Though this end point has been criticised $^{44}$ because it depends heavily on shoulder dystocia, a subjective end point, we accepted it as valid. A sensitivity analysis showed that even without inclusion of shoulder dystocia, the rates would be significantly different (data not shown).

We did not consider the combined end point in the study by Landon et $\mathrm{al}^{21}$ as valid because it included surrogate end points like concentrations of $\mathrm{C}$ peptide in cord blood. Although we considered the risk of bias in their study in general to be low, for some end points we thought the risk of bias was higher because not all randomised women were included in the analyses.

Study pool B contained trials that tested a broad spectrum of different interventions, including different forms of blood glucose monitoring and treatments with oral antidiabetic drugs. Also, the selection criteria were heterogeneous between studies. This heterogeneity, and the fact that most of the trials from pool B were at high risk of bias, makes it more difficult to draw sound inferences. It is reassuring, however, that the results from both study pools were concordant.

Another limitation concerns the transferability of the results. As most of the included studies were conducted in North America, Europe, and Australia not all ethnic groups were sufficiently represented. It remains unclear if the results found are applicable to women from, for example, South East Asia and China.

Our conclusions are also somewhat restricted as the included trials did not explicitly investigate the harms of treatment. Crowther et al reported that women in the intervention group did not worry more or less than women in the control group but did significantly better in regard to depression after birth, physical functioning, and health state utility..$^{19}$ But these analyses have a high risk of bias because a high percentage of women were not included in the analyses. Rates of 


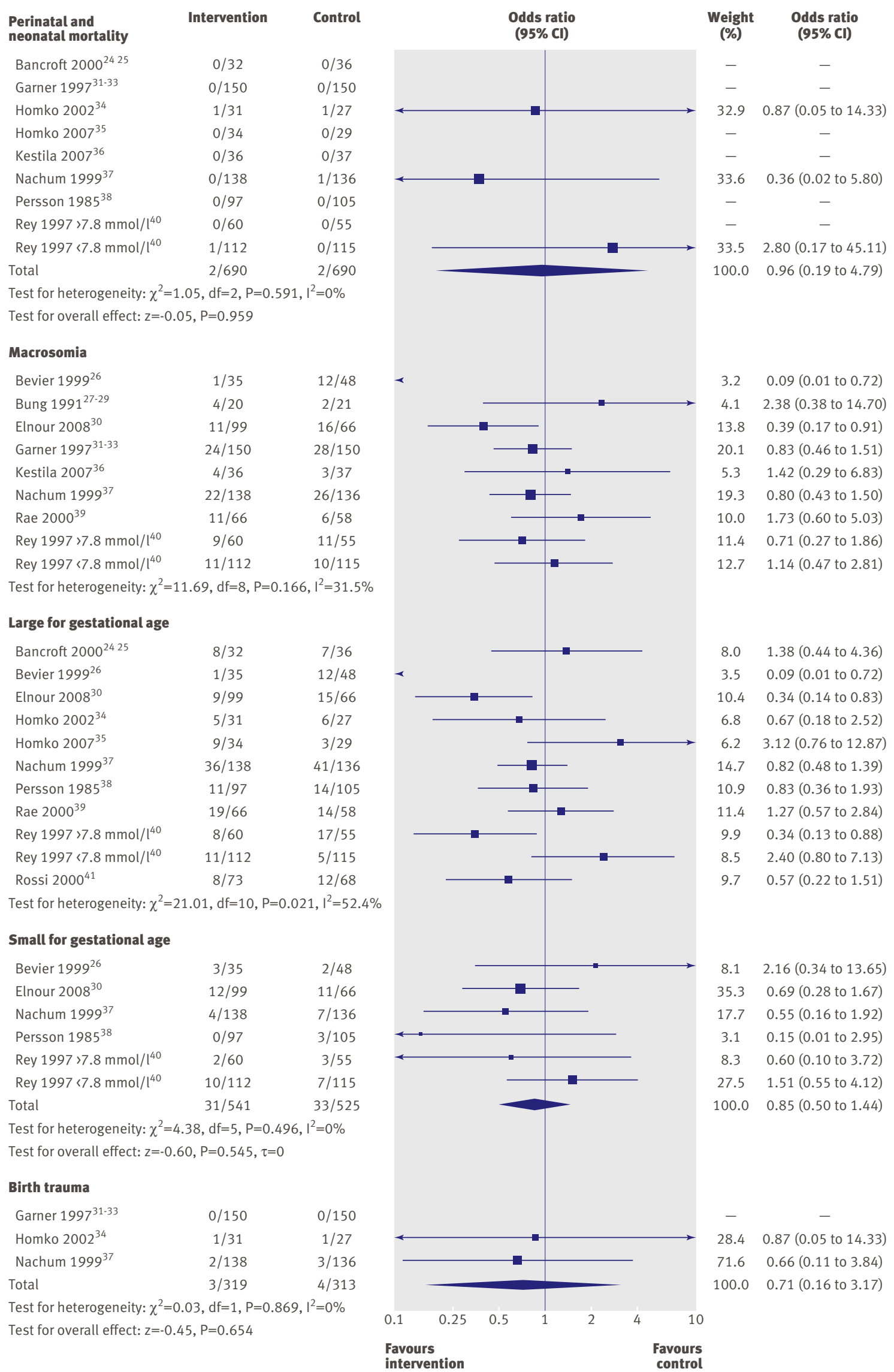

Fig 5 | Neonatal outcomes in pool B (DerSimonian and Laird random effects model, except for perinatal and neonatal morality and birth trauma, which use Peto fixed effects model) 


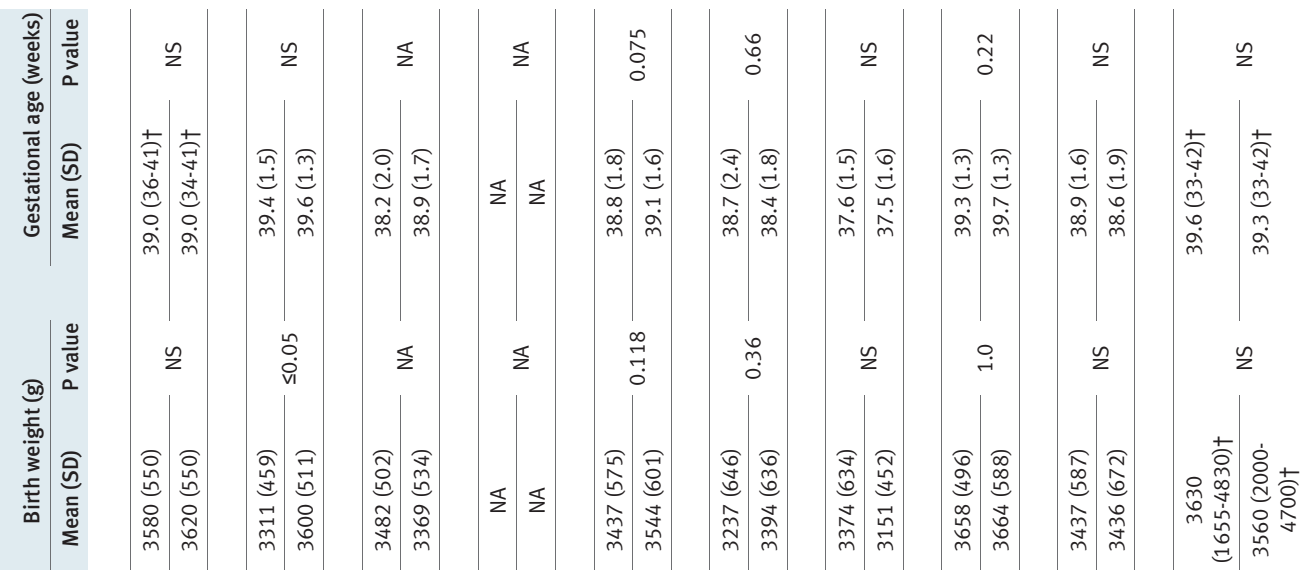

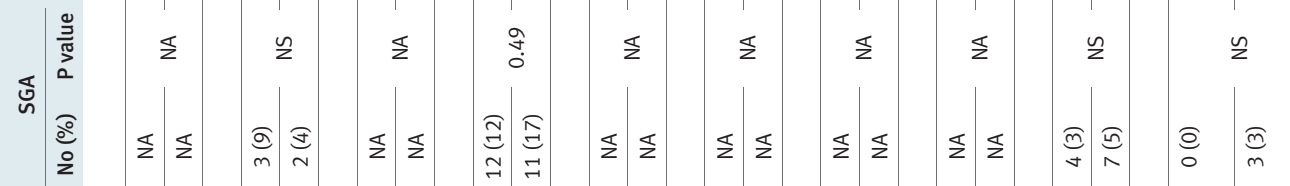

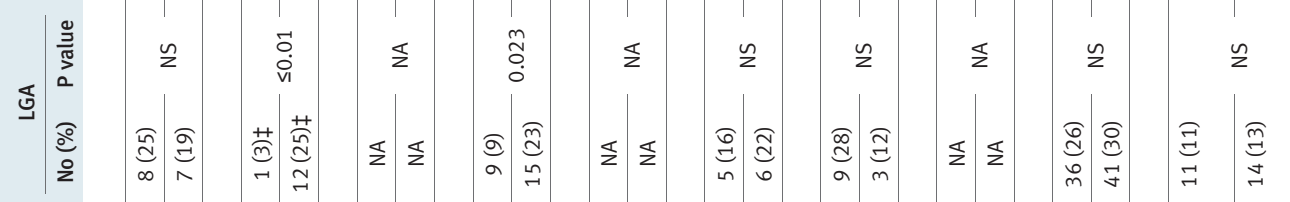

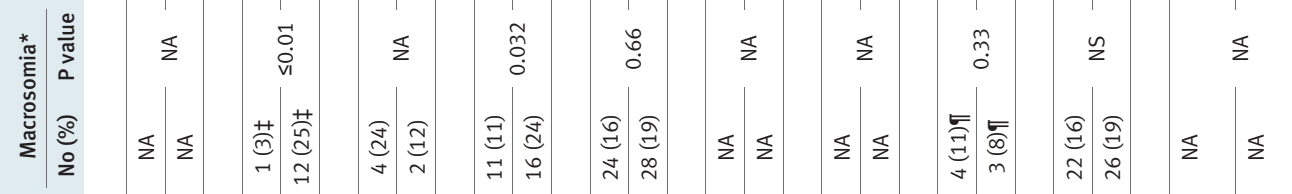

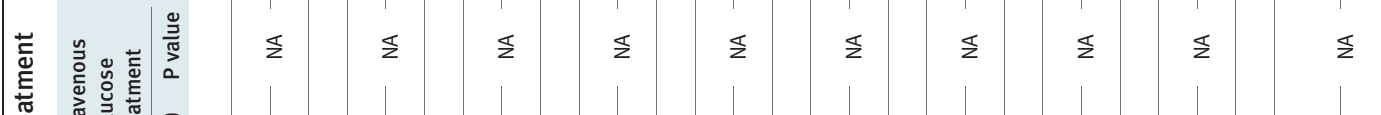

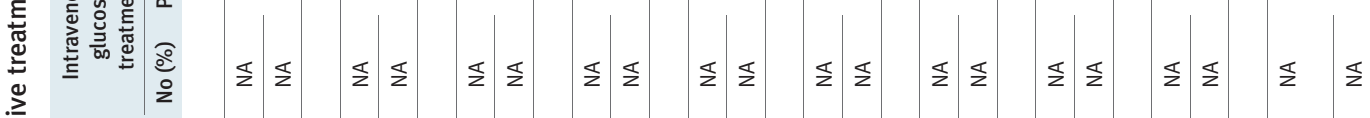

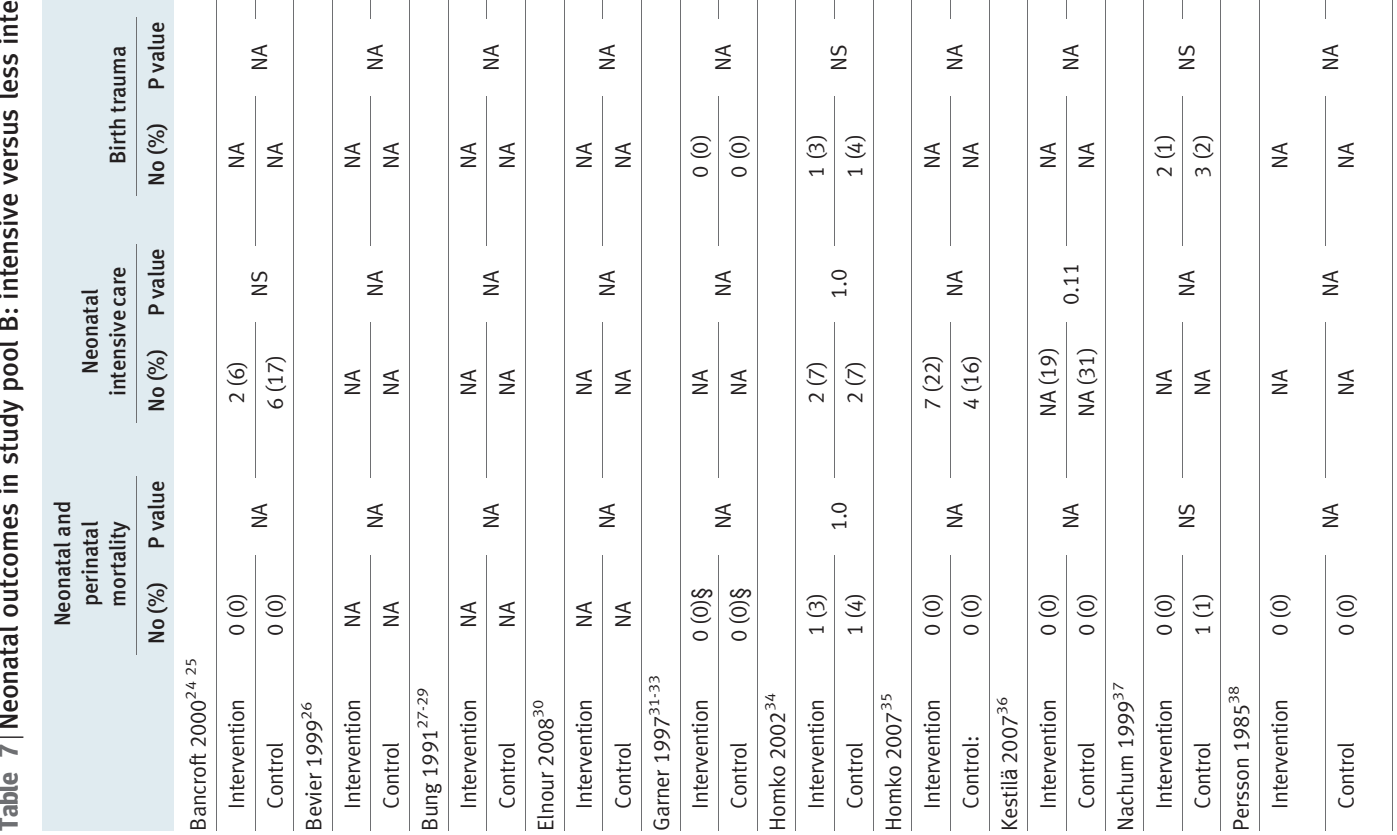




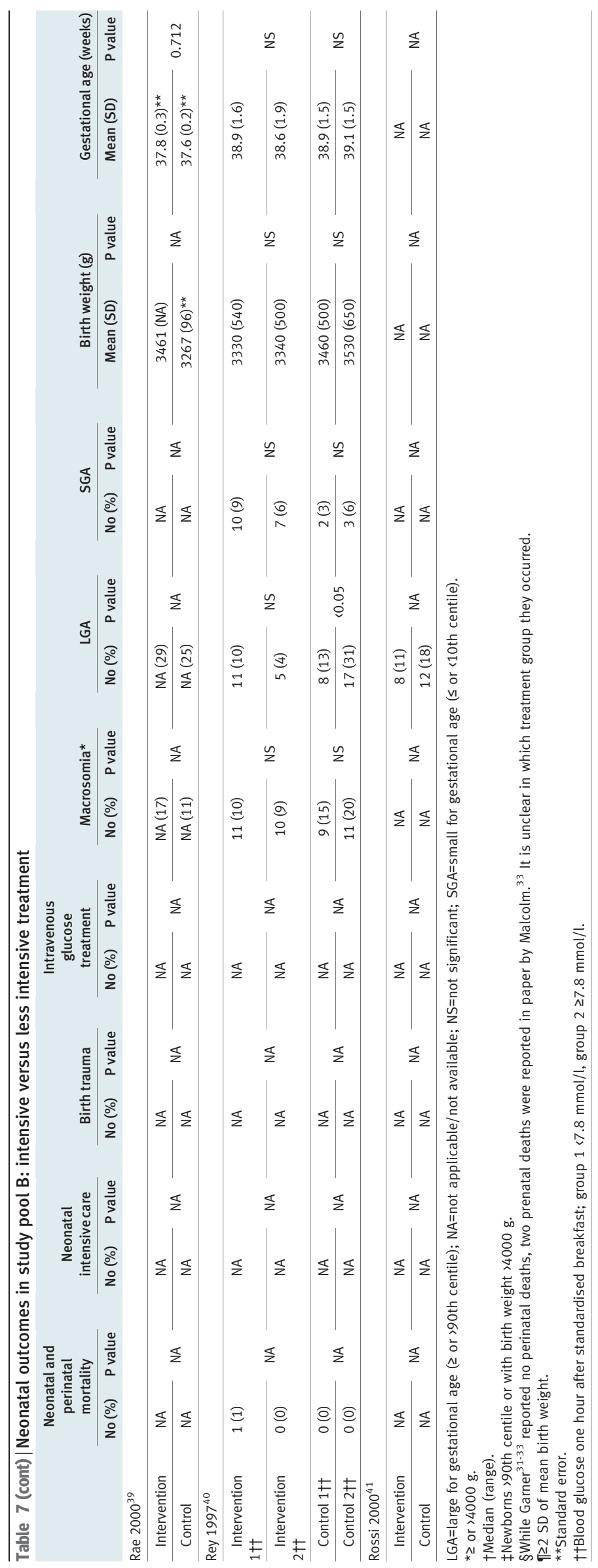

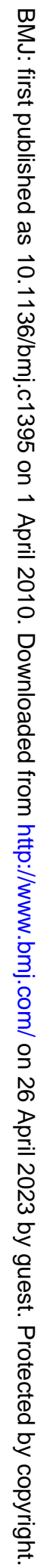




\section{WHAT IS ALREADY KNOWN ON THIS TOPIC}

Specific treatment of women with gestational diabetes mellitus is recommended to lower the risk of adverse pregnancy outcomes in the mother and baby

It is unclear which outcomes can be influenced and which women with gestational diabetes and their babies will benefit from treatment, depending on the mother's degree of carbohydrate intolerance

\section{WHAT THIS STUDY ADDS}

Treatment of gestational diabetes seems to have beneficial effects on some complications of pregnancy

The evidence of benefit is derived from trials for which women were selected by a two step strategy combining a glucose challenge test or screening for risk factors, or both, and an oral glucose tolerance test women. ${ }^{8}$ These guidelines recommend a two step screening strategy for gestational diabetes in all healthy pregnant women on the basis of risk factors and a $75 \mathrm{~g}$ oral glucose tolerance test. For diagnosis the WHO cut-off values ${ }^{9}$ are recommended.

Does the evidence support screening for gestational diabetes?

We consider there is a benefit with intensive treatment, including daily self measurement, diet, and, for some women, insulin and additional obstetric intervention. Compared with routine care this management is associated with a reduction in the incidence of shoulder dystocia and macrosomia. Currently there is less robust evidence that treatment for gestational diabetes leads to a reduction in more serious maternal or perinatal complications.

This benefit, although limited, might be seen as a justification for screening. It is not known if screening has harms serious enough to counterbalance the possible benefits of treatment. Effects can be fully judged only by screening trials, which follow up women with negative screening results. As there are no reliable screening studies available ${ }^{485}$ and we could not identify ongoing studies, we do not expect the evidence base to change much in the foreseeable future.

In our opinion proposals for screening for gestational diabetes have to take into account that some evidence of benefit of treatment is derived from trials for which women were selected by a two step strategy combining a glucose challenge test (or screening for risk factors, or both) and an oral glucose tolerance test.

Currently an international consensus for screening of gestational diabetes is being developed ${ }^{51}$ based on the risk associations reported in the HAPO study - an observational study describing the "natural" correlation between blood glucose concentration in mid-pregnancy measured by a $75 \mathrm{~g}$ two hour oral glucose tolerance test and a broad range of outcomes. ${ }^{2}$ Women and caregivers were blinded to the results of the tolerance tests. A consensus based on the HAPO data assumes that the benefits seen for women included in intervention trials can be transferred to women with a diagnosis of gestational diabetes deduced from the risk associations seen in HAPO. ${ }^{51}$

We think that the transferability of benefits cannot be taken for granted. For example, while women in all the interventional studies in pool A were selected in a two step process consisting of a $50 \mathrm{~g}$ glucose challenge test (or screening for risk factors, or both) and a second $75 \mathrm{~g}$ or $100 \mathrm{~g}$ oral glucose tolerance test, women in $\mathrm{HAPO}^{2}$ underwent only a one step $75 \mathrm{~g}$ oral glucose tolerance test. Transferability is also hampered by the fact that the studies applied different inclusion and exclusion criteria, recruited different ethnic groups, and defined outcomes differently. An indication that this might have an impact is that, although the mean fasting blood glucose concentrations in the studies of Crowther et $\mathrm{al}^{19}$ and Landon et $\mathrm{al}^{21}$ were similar $(86.5 \mathrm{mg} / \mathrm{dl} \quad(4.76 \mathrm{mmol} / \mathrm{l})$ and $86.6 \mathrm{mg} / \mathrm{dl}$ (4.77 mmol/l), respectively) and not that different 
from that in $\mathrm{HAPO}^{2}(80.9 \mathrm{mg} / \mathrm{dl}(4.46 \mathrm{mmol} / \mathrm{l}))$, the incidence of large for gestational age babies in the control groups was rather different $\left(22 \%,{ }^{19} 15 \%,{ }^{21} 9.5 \%{ }^{2}\right)$.

Studies comparing different screening strategies for gestational diabetes are needed to allow for a proper assessment of the balance of benefit and harms of screening. Pregnant women should be informed about the possible benefits as well as the uncertainties concerning screening. Recommendations for screening strategies should mirror the selection strategies of women for whom a benefit of treatment has been shown.

We thank P T Sawicki for repeated reviewing of the data and manuscript; S Droste and S Waffenschmidt for assistance with the literature search strategies; A Steinzen, M Messer, and Y Zens for help with literature screening; and E Vervölgyi, C Schürmann, and S Sturtz for help with additional analyses

Contributors: All authors contributed to the writing of the study protocol, and the interpretation of data. They also contributed in drafting the article or in revising it critically for important intellectual content and approved the final version. $\mathrm{KH}$, KK, and AS are guarantors. M Häusler contributed as a specialist in obstetrics and gynaecology in preparing the original IQWiG report. U Pueringer helped in collecting data.

Funding: This study was commissioned by the German Federal Joint Committee. KH, KJ, EM, and AS acted as consultants for the preparation of the review. For this they were reimbursed by IQWiG. KK, RB, HB, and SL (as well as PTS, SD, SW, AS, MM, YZ, EV, CS, and SS) are employees of IQWiG.

Competing interests: All authors have completed the Unified Competing Interest form at www.icmje.org/coi_disclosure.pdf (available on request from the corresponding author) and declare that all authors (KH, KK, KJ, $\mathrm{EM}, \mathrm{RB}, \mathrm{HB}, \mathrm{SL}, \mathrm{AS}$ ) have no support from any company for the submitted work, have no relationship with companies that might have an interest in the submitted work in the previous 3 years; their spouses, partners or children have no financial relationship that may be relevant to the submitted work; and have no non-financial interests that may be relevant to the submitted work.

Ethical approval: Not required.

Data sharing: The search strategy and detailed information on further materna and neonatal outcomes for studies from both pools can be found at www.iqwig. de/download/S07-01_Abschlussbericht_Screening_auf_Gestationsdiabetes.pdf.

1 Metzger BE, Coustan DR. Summary and recommendations of the Fourth International Workshop-Conference on Gestational Diabetes Mellitus. Diabetes Care 1998;21(suppl 2):161-7S.

2 Metzger BE, Lowe LP, Dyer AR, Trimble ER, Chaovarindr U, Coustan DR, et al. Hyperglycemia and adverse pregnancy outcomes. N Engl J Med 2008;358:1991-2002.

3 Bellamy L, Casas JP, Hingorani AD, Williams D. Type 2 diabetes mellitus after gestational diabetes: a systematic review and metaanalysis. Lancet 2009;373:1773-9.

4 Hillier TA, Vesco KK, Pedula KL, Beil TL, Whitlock EP, Pettitt DJ. Screening for gestational diabetes mellitus: a systematic review for the US Preventive Services Task Force. Ann Intern Med 2008;148:766-75.

5 Ferrara A. Increasing prevalence of gestational diabetes mellitus: a public health perspective. Diabetes Care 2007;30(suppl 2):141-6S

6 Deutsche Gesellschaft für Gynäkologie und Geburtshilfe. Diagnostik und Therapie des Gestationsdiabetes (GDM). 2001. www.agmfm. de/_download/unprotected/ g_04_03_04_diagnostik_therapie_gdm.pdf.

7 American Diabetes Association. Standards of medical care in diabetes: 2007. Diabetes Care 2007;30(suppl 1):4-41S

8 National Collaborating Centre for Women's and Children's Health. Antenatal care: routine care for the healthy pregnant woman. RC OG Press, 2008.

9 World Health Organization. Definition, diagnosis and classification of diabetes mellitus and its complications. Report of a WHO consultation. Part 1: diagnosis and classification of diabetes mellitus. 1999. www.diabetes.com.au/pdf/who report.pdf.

10 Canadian Diabetes Association. 2003 clinical practice guidelines for the prevention and management of diabetes in Canada. Can J Diabetes 2003;27(suppl 2):1-152S.

11 DerSimonian R, Laird N. Meta-analysis in clinical trials. Control Clin Trials 1986;7:177-88.
12 Bradburn MJ, Deeks JJ, Berlin JA, Russell Localio A. Much ado about nothing: a comparison of the performance of meta-analytical methods with rare events. Stat Med 2007;26:53-77.

13 Higgins JP, Thompson SG. Quantifying heterogeneity in a metaanalysis. Stat Med 2002;21:1539-58.

14 Higgins JP, Thompson SG, Deeks JJ, Altman DG. Measuring inconsistency in meta-analyses. BMJ 2003;327:557-60.

15 Jackson $\mathrm{D}$. The power of the standard test for the presence of heterogeneity in meta-analysis. Stat Med 2006;25:2688-99.

16 Institut für Qualität und Wirtschaftlichkeit im Gesundheitswesen. Screening auf Gestationsdiabetes. Berichtsplan S07-01. Version 1.0. IQWIG, 2007.

17 Bonomo M, Corica D, Mion E, Goncalves D, Motta G, Merati R, et al. Evaluating the therapeutic approach in pregnancies complicated by borderline glucose intolerance: a randomized clinical trial. Diabet Med 2005;22:1536-41.

18 Athukorala C, Crowther CA, Willson K. Women with gestational diabetes mellitus in the ACHOIS trial: risk factors for shoulder dystocia. Aust N Z J Obstet Gynaecol 2007;47:37-41.

19 Crowther CA, Hiller JE, Moss JR, McPhee AJ, Jeffries WS, Robinson JS. Effect of treatment of gestational diabetes mellitus on pregnancy outcomes. N Engl J Med 2005;352:2477-86.

20 Moss JR, Crowther CA, Hiller JE, Willson KJ, Robinson IS. Costs and consequences of treatment for mild gestational diabetes mellitus: evaluation from the ACHOIS randomised trial. BMC Pregnancy Childbirth 2007;7:27.

21 Landon MB, Spong CY, Thom E, Carpenter MW, Ramin SM, Casey B, et al. A multicenter, randomized trial of treatment for mild gestational diabetes. N Engl/ Med 2009;361:1339-48.

22 Langer O, Levy J, Brustman L, Anyaegbunam A, Merkatz R, Divon M. Glycemic control in gestational diabetes mellitus: how tight is tight enough; small for gestational age versus large for gestational age? Am J Obstet Gynecol 1989;161:646-53.

23 O'Sullivan JB, Gellis SS, Dandrow RV, Tenney BO. The potentia diabetic and her treatment in pregnancy. Obstet Gynecol 1966;27:683-9.

24 Bancroft K, Tuffnell DJ, Mason GC, Rogerson LJ, Mansfield M. A randomised controlled pilot study of the management of gestational impaired glucose tolerance. BJOG 2000;107:959-63.

25 Lao T, Ho LF. A randomised controlled pilot study of the management of gestational impaired glucose tolerance. BJOG 2001;108:769.

26 Bevier WC, Fischer R, Jovanovic L. Treatment of women with an abnormal glucose challenge test (but a normal oral glucose tolerance test) decreases the prevalence of macrosomia. Am J Perinatol 1999:16:269-75.

27 Bung P, Artal R, Khodiguian N. Regelmässige Bewegungstherapie be Kohlehydratstoffwechselstörungen in der Schwangerschaft: Ergebnisse einer prospektiven, randomisierten Longitudinalstudie. Geburtshilfe Frauenheilkd 1993;53:188-93.

28 Bung P, Artal R, Khodiguian N, Kjos S. Exercise in gestational diabetes: an optional therapeutic approach? Diabetes 1991;40(suppl 2):182-5S.

29 Bung P, Bung C, Artal R, Khodiguian N, Fallenstein F, Spatling L. Therapeutic exercise for insulin-requiring gestational diabetics: effects on the fetus-results of a randomized prospective longitudinal study. J Perinat Med 1993;21:125-37.

30 Elnour AA, El Mugammar I, Jaber T, Revel T, McElnay JC. Pharmaceutical care of patients with gestational diabetes mellitus. J Eval Clin Pract 2008;14:131-40.

31 Garner P, Okun N, Keely E, Wells G, Perkins S, Sylvain J, et al. A randomized controlled trial of strict glycemic control and tertiary level obstetric care versus routine obstetric care in the management of gestational diabetes: a pilot study. Am / Obstet Gynecol 1997;177:190-5.

32 Keely EJ, Malcolm JC, Hadjiyannakis S, Gaboury I, Lough G, Lawson ML. Prevalence of metabolic markers of insulin resistance in offspring of gestational diabetes pregnancies. Pediatr Diabetes 2008;9:53-9.

33 Malcolm IC, Lawson ML, Gaboury I, Lough G, Keely E. Glucose tolerance of offspring of mother with gestational diabetes mellitus in a low-risk population. Diabet Med 2006;23:565-70.

34 Homko Cl, Sivan E, Reece EA. The impact of self-monitoring of blood glucose on self-efficacy and pregnancy outcomes in women with diet-controlled gestational diabetes. Diabetes Educ 2002;28:435-43.

35 Homko CJ, Santamore WP, Whiteman V, Bower M, Berger P, Geifman-Holtzman 0, et al. Use of an internet-based telemedicine system to manage underserved women with gestational diabetes mellitus. Diabetes Technol Ther 2007;9:297-306

36 Kestila KK, Ekblad UU, Ronnemaa T. Continuous glucose monitoring versus self-monitoring of blood glucose in the treatment of gestational diabetes mellitus. Diabetes Res Clin Pract 2007;77:174-9. 
37 Nachum Z, Ben-Shlomo I, Weiner E, Shalev E. Twice daily versus fou times daily insulin dose regimens for diabetes in pregnancy: randomised controlled trial. BMJ 1999;319:1223-7.

38 Persson B, Stangenberg M, Hansson U, Nordlander E. Gestational diabetes mellitus (GDM): comparative evaluation of two treatment regimens, diet versus insulin and diet. Diabetes 1985;34(suppl 2):101-5S.

39 Rae A, Bond D, Evans S, North F, Roberman B, Walters B. A randomised controlled trial of dietary energy restriction in the management of obese women with gestational diabetes. Aust N Z Obstet Gyanecol 2000;40:416-22.

40 Rey E. Usefulness of a breakfast test in the management of women with gestational diabetes. Obstet Gynecol 1997;89:981-8.

41 Rossi G, Somigliana E, Moschetta M, Bottani B, Barbieri M, Vignali M. Adequate timing of fetal ultrasound to guide metabolic therapy in mild gestational diabetes mellitus: results from a randomized study. Acta Obstet Gynecol Scand 2000;79:649-54.

42 Yang X, Hsu-Hage BH, Dong L, Shao P, Wang H, Tian H, et al. Intensive diabetes management may improve pregnancy: outcomes in Chinese gravidas with impaired glucose tolerance. Diabetes Care 2003;26:254-5.

43 Yang X, Hsu-Hage BH, Dong L, Zhang H, Zhang C, Zhang Y. Postpartum glucose intolerance in Chinese women with gestational diabetes. Diabet Med 2003;20:687-9.

44 Montori VM, Busse JW, Permanyer-Miralda G, Ferreira I, Guyatt GH. How should clinicians interpret results reflecting the effect of an intervention on composite endpoints: should I dump this lump? ACP J Club 2005;143:A8-A9.
45 Nicholson WK, Wilson LM, Witkop CT, Baptiste-Roberts K, Bennett WL, Bolen S, et al. Therapeutic management, delivery, and postpartum risk assessment and screening in gestational diabetes. Evid Rep Technol Assess (Full Rep) 2008;162:1-96.

46 De Veciana M, Major CA, Morgan MA, Asrat T, Toohey JS, Lien JM, et al. Postprandial versus preprandial blood glucose monitoring in women with gestational diabetes mellitus requiring insulin therapy. N Engl J Med 1995;333:1237-41.

47 Jovanovic L, Ilic S, Pettitt DJ, Hugo K, Gutierrez M, Bowsher RR, et al. Metabolic and immunologic effects of insulin lispro in gestational diabetes. Diabetes Care 1999;22:1422-7.

48 Langer O, Conway DL, Berkus MD, Xenakis EM, Gonzales O. A comparison of glyburide and insulin in women with gestational diabetes mellitus. N Engl J Med 2000;343:1134-8.

49 Langer O, Yogev Y, Most O, Xenakis EM. Gestational diabetes: the consequences of not treating. Am J Obstet Gynecol 2005;192:989-97.

50 Guideline Development Group. Management of diabetes from preconception to the postnatal period: summary of NICE guidance. BMJ 2008;336:714-7.

51 Yogev Y, Metzger BE, Hod M. Establishing diagnosis of gestational diabetes mellitus: impact of the hyperglycemia and adverse pregnancy outcome study. Semin Fetal Neonatal Med 2009;14:94-10.

Accepted: 22 January 2010 